
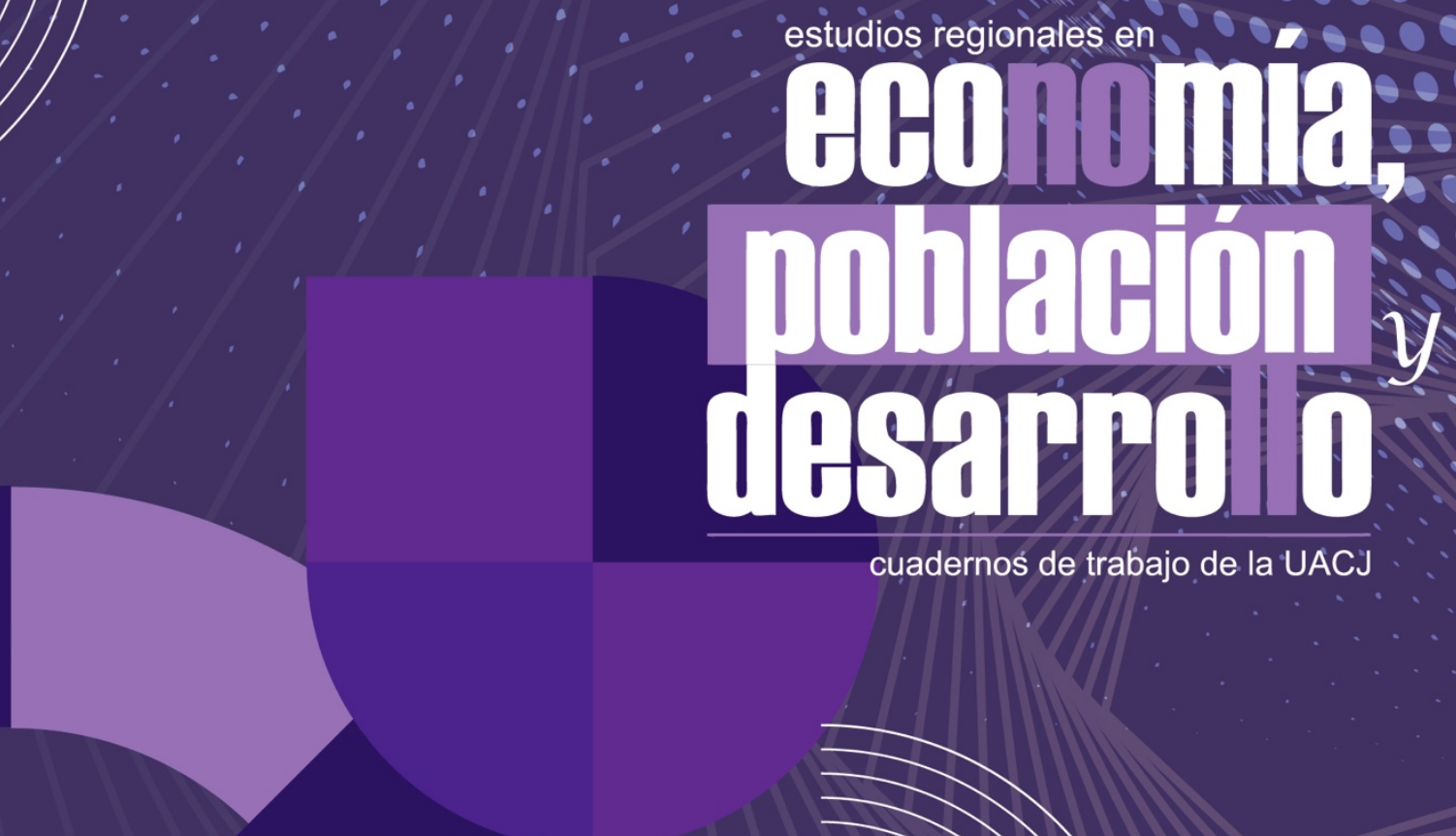

cuadernoś de trabajo de la UACJ

El impacto socioeconómico global del COVID-19: un análisis basado en brotes epidémicos para Nueva Zelanda

Alan Alejandro Zepeda Contreras y Rafael Trueba Regalado 


\title{
El impacto socioeconómico global del COVID-19: un análisis basado en brotes epidémicos para Nueva Zelanda
}

Alan Alejandro Zepeda Contreras y Rafael Trueba Regalado

\author{
UNIVERSIDAD AUTÓNOMA DE CIUDAD JUÁREZ \\ PUBLICACIÓN AFILIADA A LA \\ RED IBEROAMERICANA DE ESTUDIOS DEL DESARROLLO
}




\title{
UNIVERSIDAD AUTÓNOMA DE CIUDAD JUÁREZ
}

\author{
PUBLICACIÓN AFILIADA A LA \\ RED IBEROAMERICANA DE ESTUDIOS DEL DESARROLLO
}

Universidad Autónoma de Ciudad Juárez

2018-2024

Mtro. Juan Ignacio Camargo Nassar

Rector

Mtro. Daniel Alberto Constandse Cortez

Secretario General

Mtro. Santos Alonso Morales Muñoz

Director del Instituto de Ciencias Sociales y Administración

Mtro. Jesús Meza Vega

Director General de Comunicación Universitaria

Comité de Coordinación de la Red Iberoamericana

de Estudios del Desarrollo 2018-2020

Dra. Paulina Sanhueza Martínez (Universidad de la Frontera, Chile)

Coordinadora General

Dr. Ignacio Rodríguez Rodríguez (Universidad de la Frontera, Chile)

Secretario general

Dra. Myrna Limas Hernández

(Universidad Autónoma de Ciudad Juárez, México)

Vocal de Organización

Dr. Pablo Galaso Reca (Universidad de la República, Uruguay)

Vocal de Organización

Dr. Luis Enrique Gutiérrez Casas

Director y editor de Cuadernos de Trabajo

Estudios Regionales en Economía, Población y Desarrollo

Comité editorial

Sección internacional

Dra. Sofía Boza Martínez

(Universidad de Chile, Chile)

Dra. Olga Biosca Artiñano

(Glasgow Caledonian University, Reino Unido)

Dra. Ángeles Sánchez Díez

(Universidad Autónoma de Madrid, España)

Dr. Thomas Fullerton Mankin

(University of Texas at E1 Paso, Estados Unidos)

Dr. Adrián Rodríguez Miranda

(Universidad de la República, Uruguay)

Dra. Ikuho Kochi

(Kanazawa University, Japón)

Dr. Pablo Galaso Reca

(Universidad de la República, Uruguay)

Sección local

(Universidad Autónoma de Ciudad Juárez)

Dra. Myrna Limas Hernández

Dra. Rosa María García Almada

Dr. Raúl Alberto Ponce Rodríguez

Dr. Isaac Leobardo Sánchez Juárez

Dr. Héctor Alonso Barajas Bustillos

Dr. Juan Carlos Medina Guirado

Mtra. María Del Socorro Velázquez Vargas

Diseño de cubierta

Abigail Bautista
Estudios Regionales en Economía, Población

y Desarrollo. Cuadernos de Trabajo de la UACJ

ISSN 2007-3739

Número 62. Marzo - Abril 2021

El impacto socioeconómico global del COVID-19: un análisis basado en brotes epidémicos para Nueva Zelanda

Alan Alejandro Zepeda Contreras y Rafael Trueba Regalado

Universidad Autónoma de Ciudad Juárez

Estudios Regionales en Economía, Población y Desarrollo.

Cuadernos de Trabajo de la UACJ

Año 11, No. 62 marzo - abril 2021, es una publicación bimestral editada por la Universidad Autónoma de Ciudad Juárez a través del Cuerpo Académico de Estudios Regionales en Economía, Población y Desarrollo del Instituto de Ciencias Sociales y Administración. Redacción: Avenida Universidad y H. Colegio Militar, Zona Chamizal s/n., C.P. 32300, Ciudad Juárez, Chihuahua, México.

Teléfonos: (656) 688-38-00, ext.3792. Correo electrónico: igtz@uacj.mx. Editor responsable: Luis Enrique Gutiérrez Casas. Reserva de derechos al uso exclusivo: edición impresa, ISSN 2007-3739., edición digital, No. de reserva 04-2019-050218151500. Impresa por Studio Los Dorados, calle Del Campanario, número 820-2, Santa Cecilia, C.P. 32350, Cd. Juárez, Chihuahua. Distribuidor: Subdirección de Gestión de Proyecto y Marketing Editorial. Ave. Plutarco Elías Calles 1210, Foviste Chamizal, C.P. 32310, Ciudad Juárez, Chihuahua. Este número se terminó de imprimir el 15 de febrero 2021 con un tiraje de 120 ejempares.

Los ensayos publicados son responsabilidad exclusiva de sus autores.

Se autoriza la reproducción total o parcial bajo condición de citar la fuente.

\section{Registrada en: EBSCO RePEC UAC] Thevistas Electrónicas}

Publicación afiliada a la Red Iberoamericana de Estudios del Desarrollo

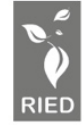

Universidad Autónoma de Ciudad Juárez

Ave Plutarco Elías Calles 1210

Foviste Chamizal, C.P. 32310

Ciudad Juárez, Chihuahua, México

www.uacj.mx

(C) Universidad Autónoma de Ciudad Juárez 


\title{
El impacto socioeconómico global del COVID-19: un análisis basado en brotes epidémicos para Nueva Zelanda
}

\author{
Alan Alejandro Zepeda Contreras * y Rafael Trueba Regalado **
}

\begin{abstract}
Resumen
El trabajo tiene como objetivo determinar los impactos socioeconómicos globales que han ocasionado el síndrome respiratorio agudo severo (SARS), la influenza HIN1, el síndrome respiratorio del Medio Oriente (MERS) y en especial el coronavirus (COVID-2019) en diversos periodos de análisis, haciendo hincapié en cómo se han presentado estos comportamientos en el caso neozelandés. El enfoque metodológico de la investigación fue mixto, se utilizaron bases estadísticas para el análisis de las variables estudiadas, así como diversas fuentes de literatura. Los resultados indican que el COVID-19 es el virus que más efectos socioeconómicos globales ha generado en términos de crecimiento económico, desempleo y comercio internacional. La nación menos perjudicada por los diferentes brotes epidémicos es Nueva Zelanda, esto se atribuye a que su población y territorio son pequeños, con crecimiento y desarrollo económico constante, y sus habitantes poseen un alto grado de educación. Estos factores impulsaron la toma de decisiones del gobierno de una forma eficiente para crear un adecuado protocolo de salud pública, controlar los contagios y amortiguar la situación económica.
\end{abstract}

Palabras clave: COVID-19, brotes epidémicos, salud pública, economía, Nueva Zelanda.

\begin{abstract}
The paper aims to determine the global socioeconomic impacts that have caused the Severe Acute Respiratory Syndrome (SARS), the influenza H1N, the Middle East Respiratory Syndrome (MERS) and especially the coronavirus 19 (COVID-2019) in various analysis periods, emphasizing how these behaviors have been presented in the New Zealander case. The methodological approach of the research was mixed, statistical bases were used for the analysis of the variables studied, as well as various sources of literature. The results indicate that COVID-19 is the virus that has generated the most global socio-economic effects in terms of economic growth, unemployment, and international trade. New Zealand is the least nation affected by the different epidemic outbreaks, this is explained because his population and territory are small, with constant economic growth and development, and also has inhabitants with a high degree of education. These factors drove the government's decision-making in an efficient way to create an adequate public health protocol, control the contagions and cushion the economic situation.
\end{abstract}

Keywords: COVID-19, epidemic outbreaks, public health, economics, New Zealand.

JEL: $115, F 63,056$.

Recibido en: Noviembre de 2020.

Aprobado en: Enero de 2021.

\footnotetext{
* Licenciado en Negocios Internacionales por el Instituto Tecnológico y de Estudios Superiores de Monterrey, Campus Morelia. Correo electrónico: alan_zepeda1298@hotmail.com.

** Profesor de la Escuela de Ciencias Sociales y Gobierno del Instituto Tecnológico y de Estudios Superiores de Monterrey, Campus Morelia. Integrante de la Red Iberoamericana de Estudios del Desarrollo (RIED). Correo electrónico: rafatrueba_59@tec.mx.
} 


\section{Introducción.}

La pandemia del COVID-19 ha generado innumerables desafíos socioeconómicos para todos los países en el planeta, visibilizando la vulnerabilidad que tiene nuestra sociedad ante eventos atípicos como éste, ocasionando procesos de cuarentena. En ese sentido, las economías se han cerrado y paralizado generando la interrupción de las actividades productivas y la consiguiente disminución de demanda. Actualmente, la CEPAL (2020) indicó que la tasa de crecimiento de la economía mundial disminuiría al 1\%, siendo este un escenario de los más alentadores bajo el contexto de crisis.

Sin embargo, a medida que la pandemia se fue extendiendo, las previsiones fueron reduciendo el crecimiento económico esperado. Las estimaciones del Banco Mundial (BM) (2020), indican que la economía global se reducirá en 5\%, este comportamiento representa la peor crisis desde la Segunda Guerra Mundial. Los efectos socioeconómicos comienzan a ser visibles en los despidos masivos a nivel global, la disminución del empleo, la caída del comercio, las finanzas, el nivel educativo, los sistemas de salud, etc. La magnitud de las perturbaciones variará en función de la región que se estudie. Por ello, el objetivo de esta investigación fue analizar los impactos socioeconómicos globales de diferentes virus, resaltando el COVID 19 y haciendo énfasis en el caso de Nueva Zelanda ${ }^{2}$ para identificar qué tan perjudicada se ha visto su economía nacional, reconociendo a este país como un referente a nivel mundial en el control no sólo del COVID-19, sino también de brotes epidémicos pasados.

La investigación generó información socioeconómica (crecimiento económico, desempleo y comercio internacional) de los efectos del COVID-19, además de tres virus: el SARS, la influenza H1N1 y el MERS. Éstos fueron seleccionados por sus efectos similares a nivel global, a su vez, porque pertenecen al subgrupo viral del betacoronavirus, siendo éstos virus zoonóticos (para el género betacoronavirus) con un comportamiento similar al de una pandemia, contemplando la tasa de letalidad (TL) en el análisis.

Una vez examinada la información, se compararon los periodos en donde se presentaron los virus y sus brotes en relación con los siguientes indicadores socioeconómicos ${ }^{3}$ : el producto interno

\footnotetext{
${ }^{1}$ Este trabajo surgió de la elaboración de un proyecto a pedido de la empresa The Shipper con sede en Auckland, Nueva Zelanda, con el fin de comprender la situación actual del mercado internacional para sobrellevar problemas financieros.

${ }^{2}$ Este país se ubica geográficamente en Oceanía. Tiene una superficie de $268.838 \mathrm{~km}^{2}$. En 2019 contaba con una población de 4.9 millones de habitantes representando una densidad de la población de 18.3 habitantes por $\mathrm{km}^{2}$ (Díaz, 2019).

${ }^{3}$ Los indicadores se estudiaron en función de cada uno de los virus analizados, siguiendo un orden cronológico, pasando del brote de SARS en 2002, a la influenza en 2008, al MERS en 2012 y, por último, el COVID-19 en 2020 .
} 
bruto (PIB), la tasa de desempleo, importaciones (IMP) y exportaciones (EXP) de productos y servicios. El análisis se abordó desde una perspectiva general (promedio global) y una perspectiva particular (Nueva Zelanda) a fin de comprender la situación actual del mercado internacional y los comportamientos en el país neozelandés.

En este orden de ideas, el contenido del trabajo es el siguiente: primeramente, se aborda el marco teórico-conceptual de la investigación, resaltando las principales características para comprender conceptualmente a los virus y los indicadores estudiados, así como el crecimiento y desarrollo económico. En seguida, se plantea el enfoque metodológico del estudio, en donde se señalan los procesos de sistematización de las bases estadísticas utilizadas y los cálculos realizados. Posteriormente, se comentan los resultados, haciendo énfasis en cómo se presentaron los virus en términos de salud pública y los impactos económicos estudiados a nivel global al respecto de Nueva Zelanda. Por último, se contemplan las conclusiones.

\section{$\rightarrow$ 2. Hacia la construcción del marco teórico-conceptual.}

Un virus puede entenderse como uno de los innumerables grupos de agentes infecciosos submicroscópicos que tienden a ser considerados como moléculas complejas no vivas que contienen una capa de proteína que rodea un núcleo de $\mathrm{ARN}$ o $\mathrm{ADN}$; estas moléculas pueden crecer y multiplicarse sólo a través de células vivas y causar varias enfermedades importantes en los seres humanos, animales y plantas (Merriam-Webster Dictionary, 2020).

Los virus pueden separarse en numerosos grupos de familias como los Coronaviridae, en éstos la subfamilia Orthocoronavirinae constituye los coronavirus. De manera similar, existe la familia Orthomyxoviridae, donde el género Alphainfluenzavirus (Influenzavirus A) constituye una parte y es responsable de causar la influenza; estos son la filogenia y la taxonomía de los virus seleccionados para ser analizados en esta investigación. La filogenia puede definirse como el estudio de las relaciones de parentesco en grupos de organismos, ya sea vivos o extintos (Haque, 2008). La taxonomía, en cambio, se refiere tanto a la teoría como a la práctica de agrupar y disponer individuos y grupos para nombrarlos y crear una clasificación (Judd, Campbell, Kellogg, Stevens y Donoghue, 2007). Los coronavirus pueden definirse como un grupo de virus que causan enfermedades graves como el SARS, así como varias infecciones respiratorias y gastrointestinales en una creciente variedad de mamíferos y aves (Denison, Graham, Donaldson, Eckerle y Baric, 2011). 
Dentro de los virus ${ }^{4}$ existe un subgrupo conocido como betacoronavirus. Éste según los Centros para el Control y la Prevención de Enfermedades de los Estados Unidos (CDC) es uno de los cuatro géneros dentro de las especies de coronavirus, de origen zoonótico (transmisible de animales a humanos), y es el género del que forman parte el coronavirus del síndrome respiratorio agudo severo (SARS-CoV), el coronavirus del síndrome respiratorio del Medio Oriente (MERS-CoV) y el coronavirus del síndrome respiratorio agudo severo 2 (SARS-CoV-2). Por otro lado, existen los influenzavirus (que son Orthomyxoviridae), en los que los alfainfluenzavirus forman parte y se definen como un grupo de virus, con una filogenia y una distribución muy diversas y poco claras aún, responsables de causar frecuentes epidemias entre los mamíferos y las aves, incluidos los seres humanos donde la influenza causa una serie de infecciones respiratorias y varios síntomas similares a los de la gripe estacional (Mq King, Adams, Carstens y Lefkowitz, 2011), en este rubro se encuentra el virus de la influenza A subtipo H1N1 (la influenza). Todos los virus mencionados anteriormente han generado diferentes impactos socioeconómicos negativos a nivel global, por ello, es necesario conocer algunos aspectos teóricos en estos términos para relacionarlos con la TL (cantidad de personas que mueren por una enfermedad en un periodo determinado) (Mq King, Adams, Carstens y Lefkowitz, 2011).

En esa orientación, el crecimiento económico se interpreta como el incremento en la utilidad, o el valor de los bienes y servicios finales, producidos por una economía (de un país o región) en un lapso de tiempo específico (normalmente de un año) (Parkin, 2018). Se entiende como un cambio cuantitativo en la economía de un país y se mide con el PIB. Este indicador se utilizó en el presente trabajo para contemplar el crecimiento económico en relación a los virus analizados y sus brotes.

Entonces, el $\mathrm{PIB}^{5}$ se concibe como la medición del valor monetario de los bienes y servicios finales de un país durante un período de tiempo determinado (OCDE, 2020). Dos de sus componentes principales son las EXP (acción de enviar una mercancía nacional para su venta en el extranjero) y las IMP (acción de permitir el ingreso de una mercancía extrajera para su venta en la economía nacional) (Parkin, 2018) estudiados en el presente análisis. Por otro lado, también se utilizó el desempleo (población en edad de trabajar y con disposición a laborar, pero no tiene empleo) (Parkin, 2018), para hacer más evidente el impacto socioeconómico que han tenido los virus.

\footnotetext{
${ }^{4}$ En referencia a los virus analizados, el SARS puede entenderse como la enfermedad generada a partir del SARS-CoV; el MERS como la enfermedad causada por el MERS-CoV; el COVID-19 como la enfermedad originada por el nuevo coronavirus SARS-CoV-2, y la influenza como la enfermedad causada por el virus de la influenza (Merriam-Webster Dictionary, 2020).

${ }^{5}$ El PIB como indicador comprende las exportaciones netas (EXP menos IMP), la inversión, el consumo y el gasto público. Es controversial porque no contempla la distribución del ingreso para mejorar el bienestar de la población que habita en un territorio.
} 
Ahora bien, una postura que incorpora los cambios cualitativos en la calidad de vida de las personas es el desarrollo económico, este proceso se asimila como progreso social y menor desigualdad económica, que prospera en el reordenamiento institucional y económico, priorizando el bienestar social y el medio ambiente (Guillén, 2007). Todos estos criterios son cruciales para este artículo, ya que bajo este enfoque es que se pueden asimilar estrategias de políticas públicas para amortiguar los impactos económicos que han generado los virus y en particular el COVID-19.

\section{$\rightarrow$ 3. Diseño metodológico.}

Para obtener la información que se integra en la presente investigación se procedió a realizar una revisión de la literatura sobre los diferentes virus estudiados y los impactos socioeconómicos que han generado sus brotes, a su vez, se realizó una extensa consulta y sistematización de datos cuantitativos. ${ }^{6}$ La información reunida se obtuvo de organizaciones multilaterales, libros electrónicos, diccionarios y artículos científicos.

El principal recurso utilizado para reunir la base de datos fue Oxford Economics (OE), en particular se obtuvo del Banco de Datos Económicos Globales para cada una de las economías a fin de contemplar el comportamiento del crecimiento económico (siendo esta la primer variable

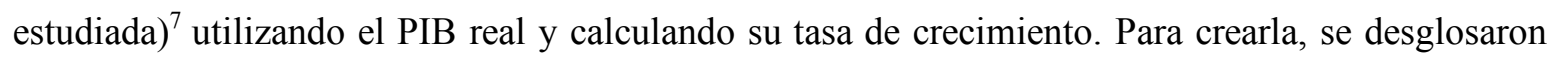
los porcentajes obtenidos por país, del año más antiguo al más reciente. Después, se calculó el promedio de los porcentajes de crecimiento por trimestre para obtener el "promedio mundial". También, se aplicó el mismo proceso para Nueva Zelanda.

En lo que respecta al desempleo como segunda variable, la información también se recopiló de OE en el Banco de Datos Económicos Globales. Los datos se tomaron directamente de la tasa de desempleo. La tercera variable fue el comercio internacional (que considera las IMP y EXP de bienes y servicios) y se obtuvo de la misma fuente para mantener la homogeneidad, en una escala de millones de dólares estadounidenses. Los datos ${ }^{8}$ se sistematizaron en períodos trimestrales en todas las variables (Office for National Statistics, 2017).

\footnotetext{
${ }^{6}$ Se trabajó con más de 50,000 datos para construir el análisis de las variables.

${ }^{7}$ Los países seleccionados para constituir las variables son: Canadá, Estados Unidos, México, Brasil, Colombia, Chile, Argentina, Nueva Zelanda, Australia, Indonesia, Tailandia, Alemania, Francia, España, Austria, Italia, Reino Unido, Noruega, Suecia, Finlandia, China, Corea del Sur, Japón, India, Rusia, Grecia, Israel, Arabia Saudita, Egipto, Marruecos, Sudáfrica y los Países Bajos.

${ }^{8}$ Para obtener el porcentaje de cambio entre valores, cada período se dividió por su trimestre anterior, restando una unidad del resultado; después de hacer esto con todos los países y variables, los resultados dentro del mismo
} 
Por último, se compararon los datos de las tres variables en una escala global al respecto de Nueva Zelanda por trimestre para producir los gráficos del texto, con el fin de comparar los impactos en la economía mundial y neozelandesa en los periodos relacionados al SARS en 2002-2004, a la influenza en 2008-2011, al MERS en 2012-2014 y al COVID-19 en 2019-2020, con proyecciones al 2022.

\section{Resultados de la investigación.}

\subsection{Impactos del SARS en la salud pública global.}

En lo que respecta a las amenazas para la salud pública relacionadas con el SARS y su comparación con el actual COVID-19, es necesario afirmar en primer lugar que, aunque ambos virus pertenecen a la misma especie en términos de filogenia, por lo que tienen una clasificación similar en el sistema taxonómico creado para estos virus, las enfermedades causadas por ellos son bastante diferentes, ya que sus similitudes no son patológicas (Mandavkar, 2020). El SARS presentó un promedio de riesgo de TL del 11\% en todo el mundo (Chan-Yeung y Xu, 2003). Esta enfermedad causó un total aproximado de 8,098 casos globales, con un número de muertes de 774 personas como resultado en el momento en que fue contenida (CDC, 2020).

\subsection{Impactos socioeconómicos globales del SARS: el caso de Nueva Zelanda.}

\subsubsection{Comportamiento del crecimiento económico en el contexto del SARS.}

En la Figura 1 se observan tres periodos importantes, éstos vienen después de los últimos meses de 2002 en el cuarto trimestre $(\mathrm{Q} 4)^{9}$, que es cuando comenzó el brote de SARS en China durante finales de año; estos son el primer trimestre de 2003 del promedio global y el segundo trimestre de 2003 en Nueva Zelanda, justo antes de la contención del brote en julio, así como el segundo trimestre de 2004 cuando había pasado medio año desde que el SARS había sido controlado.

Estos períodos son importantes, ya que retratan momentos específicos de perturbación económica en la tasa de crecimiento del PIB real dentro de los trimestres en comparación con el comportamiento general en el período de tiempo, mostrando una línea de tendencia negativa en el crecimiento del PIB real en Nueva Zelanda que osciló de 2.82\% como el registro más bajo hasta 6.07\%

período de tiempo para cada país formaron el promedio global usado para hacer comparaciones con el comportamiento de Nueva Zelanda.

${ }^{9} \mathrm{Q}$ se refiere a los trimestres y representa un período de tres meses dentro de un año; hay cuatro trimestres por año. Q4 representa los valores del cuarto trimestre de un año específico considerando octubre, noviembre y diciembre. 
como el comportamiento más elevado. El promedio global presentó una tendencia positiva en el periodo 2002-2004, misma que se encuentra en un rango de $1.36 \%$ hasta $4.22 \%$; a finales de 2002 y 2003 hubo una caída del 2.33\% en el crecimiento del PIB real para Nueva Zelanda, mientras que el promedio mundial tuvo un incremento de $0.65 \%$ en el mismo periodo con una disminución de $0.32 \%$ entre Q1 y Q2 del 2003, donde estos periodos de tiempo consideran la aparición del SARS y el comienzo del brote a nivel mundial.

Figura 1

\section{Tasa de crecimiento del PIB real 2002-2004 (periodo SARS) ${ }^{10}$}

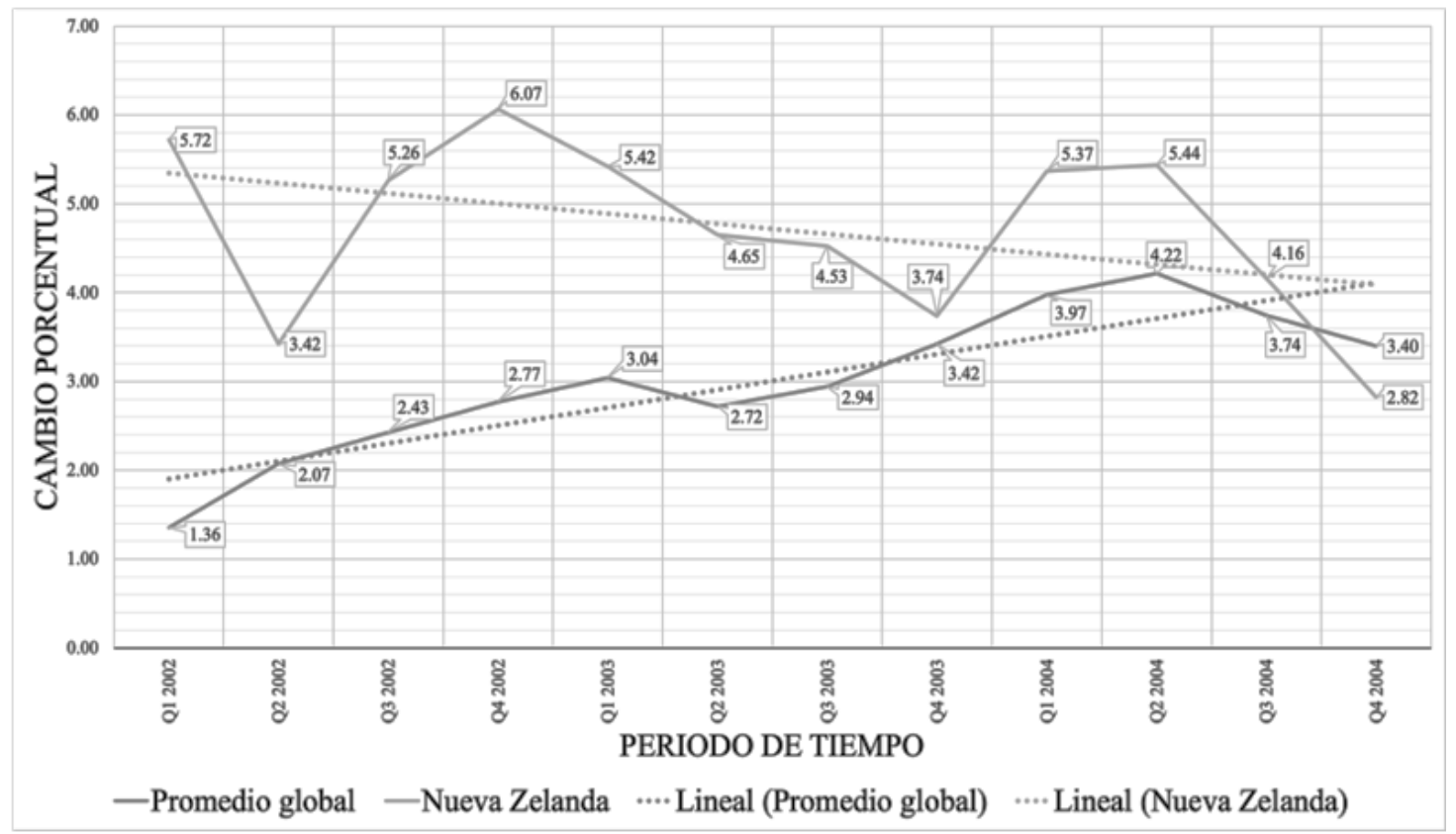

Fuente: Elaboración propia con base en Oxford Economics, Banco de Datos Económicos Globales, 2002-2004.

\footnotetext{
${ }^{10}$ El PIB real global para las naciones analizadas osciló anualmente de 30,017,689.0 (miles de millones de dólares) en 2002 hasta alcanzar la cifra de 37,525,412.4 en 2004. Con una tasa de crecimiento promedio anual durante el periodo analizado de $3.0 \%$. Por su parte el PIB real anual de Nueva Zelanda registró un comportamiento de 62,050.0 (miles de millones de dólares) en 2002 hasta 101,562.4 en 2004. Presentando un crecimiento promedio anual de $4.1 \%$.
} 
Una observación importante es que Nueva Zelanda muestra una tendencia decreciente durante la mayor parte de 2002-2004; no obstante, desde que el brote de SARS comenzó a finales de 2002, sólo se notificó un caso en Nueva Zelanda y desde entonces no se han mencionado más registros. La tendencia negativa del PIB real en el país no se relaciona con contagios locales en comparación con el promedio mundial, en el que los casos fueron aumentando en varias naciones (Chan-Yeung, y $\mathrm{Xu}, 2003)$. El SARS tuvo efectos en el crecimiento económico de Nueva Zelanda, siendo que el comportamiento negativo en el país del Pacífico Sur se relaciona con un conjunto de factores: disrupciones de viaje e incertidumbre debido a los conflictos por la guerra en Irak, el brote de SARS a nivel mundial y los efectos del clima seco en la producción de electricidad y la producción agrícola (The Treasury New Zealand, 2004).

En consecuencia al brote de SARS, la OMS emitió su primer aviso general sobre viajes el 15 de marzo de 2003, en el que aconsejaba a las personas evitar viajar a lugares como Hong Kong y Guangdong, lo que constituyó un acontecimiento importante, ya que esta organización no había hecho tal cosa en el pasado, siendo esta la primera emisión de avisos sobre viajes en zonas geográficas específicas y desencadenando una serie de medidas de seguridad al viajar, entre ellas permanecer en casa durante un período de cuarentena de 14 días y usar mascarillas (McKercher y Chon, 2004).

Durante los tres primeros meses de 2003, las conmociones iniciales afectaron a zonas como Hong Kong, provocando una caída del 15\% en la demanda de las industrias expuestas del sector de servicios para las ventas al por menor y un aumento del $5 \%$ en los costos de las actividades expuestas en el mismo sector. Este acontecimiento es el mayor factor que contribuye a la pérdida de la tasa de crecimiento del PIB real, como se ve entre el Q1 y el Q2 de 2003 (Lee y McKibbin, 2004). Posteriormente, se observó que el promedio mundial presenta un crecimiento del $0.70 \%$ entre abril y diciembre de 2003 para el PIB real, alcanzando un $3.42 \%$ de crecimiento porcentual para finales de 2003; esto, debido a que Hong Kong reaccionó rápidamente a las circunstancias adversas creando iniciativas como Individual Visit Scheme para los visitantes de China a su país, que se firmó en julio para aumentar el turismo, apoyando la recuperación económica (Government of the Hong Kong Special Administrative Region, 2003).

Por otra parte, Nueva Zelanda muestra un crecimiento porcentual del PIB real de $0.72 \%$ durante el mismo período, llegando a 5.37\% para finales de 2003; anteriormente, tuvo una caída del $0.91 \%$ de crecimiento entre abril y septiembre del 2003 con una gran recuperación durante los últimos tres meses del año. En otras palabras, los datos muestran que el SARS representó un evento atípico que afectó el crecimiento porcentual del PIB real en el país, ya que hubo tasas negativas de crecimiento, relacionadas a esta enfermedad de manera indirecta aun cuando no tuvo un aumento de casos locales en comparación con áreas con altas tasas de infección como Hong Kong. 
En relación con la caída presentada en el promedio mundial en los trimestres primero y segundo del 2003, Asia sufrió una disminución en la llegada de turistas de entre el 30\% y el 80\%, con la cancelación de numerosos vuelos; además, los índices de los mercados de valores asiáticos disminuyeron en un 15\% motivados por la incertidumbre en el mercado debido al SARS. El BM comunicó una pérdida aproximada del 2\% del PIB real de Asia en el segundo trimestre de 2003 durante el brote.

Después de esto, se observa que el PIB real comenzó a recuperarse a lo largo del 2003 e inicios del 2004; en este último año, hay una importante disminución del crecimiento porcentual en el segundo trimestre, con un descenso del $2.62 \%$ para Nueva Zelanda y del $0.82 \%$ para el promedio mundial a finales del año, este se atribuye a los efectos negativos en la economía mundial como resultado del SARS y otros factores. Las líneas de tendencia en las escalas exhibieron un comportamiento opuesto entre sí del crecimiento en el PIB real, esto se entiende como los efectos analizados únicamente en un periodo en particular, con afectaciones económicas para regiones como Asia y el Pacífico que deben ser tomadas en cuenta con seriedad en el escenario de la actual pandemia por COVID-19. Un claro ejemplo del problema son las mediciones del Banco Asiático de Desarrollo, que estimó una pérdida económica de 59,000 millones de dólares estadounidenses con pérdidas asociadas a las perturbaciones en la inversión, los viajes, el comercio, la cadena de suministro y los cambios en el comportamiento de los consumidores (Baric, 2008).

\subsubsection{Comportamiento del desempleo en el contexto del SARS.}

Durante el período 2002-2004, el desempleo en el promedio mundial mantuvo un comportamiento constante entre el $7.8 \%$ y el $8.5 \%$, lo cual se observa en la línea de tendencia con un comportamiento decreciente de principio a fin (ver Figura 2). Entre el cuarto trimestre de 2002 y el primer trimestre de 2003 se produjo un aumento del desempleo en el promedio mundial, que coincide con el comienzo del brote durante noviembre de 2002. De la misma manera, Nueva Zelanda experimentó una tendencia decreciente con el desempleo, ya que la tasa porcentual pasó del 5.3\% durante el primer trimestre de 2002 a 3.7\% a finales del cuarto trimestre de 2004.

Es importante señalar que el SARS no presentó inconvenientes económicos en el conjunto del año, sólo en determinados meses, teniendo una ligera pero constante disminución del desempleo desde el primer trimestre de 2003, cuando el virus había empezado a propagarse, hasta finales de 2003 para el promedio mundial y el Q3 de 2003 para Nueva Zelanda, con una disminución en la tasa de desempleo del $0.30 \%$ para ambos casos entre 2003 y 2004, lo que representó un comportamiento decreciente de esta variable durante 2003, aún y cuando fue el año en que el SARS ganó terreno en cuanto a número de infecciones de febrero a julio (CDC, 2013). 
A medida que el SARS se extendió por todo el mundo y causó graves repercusiones a corto plazo en las actividades económicas de China y Hong Kong, también aumentó el desempleo como consecuencia de ello. De hecho, el aumento del desempleo y el subempleo en el promedio global durante los trimestres primero y segundo de 2003 en comparación con 2002 se debió a un lento repunte en el mundo industrializado, a las repercusiones del SARS en el empleo de Asia y a los efectos de los conflictos armados, como la guerra de Irak (OIT, 2004).

Figura 2

Tasa de desempleo 2002-2004 (periodo SARS)

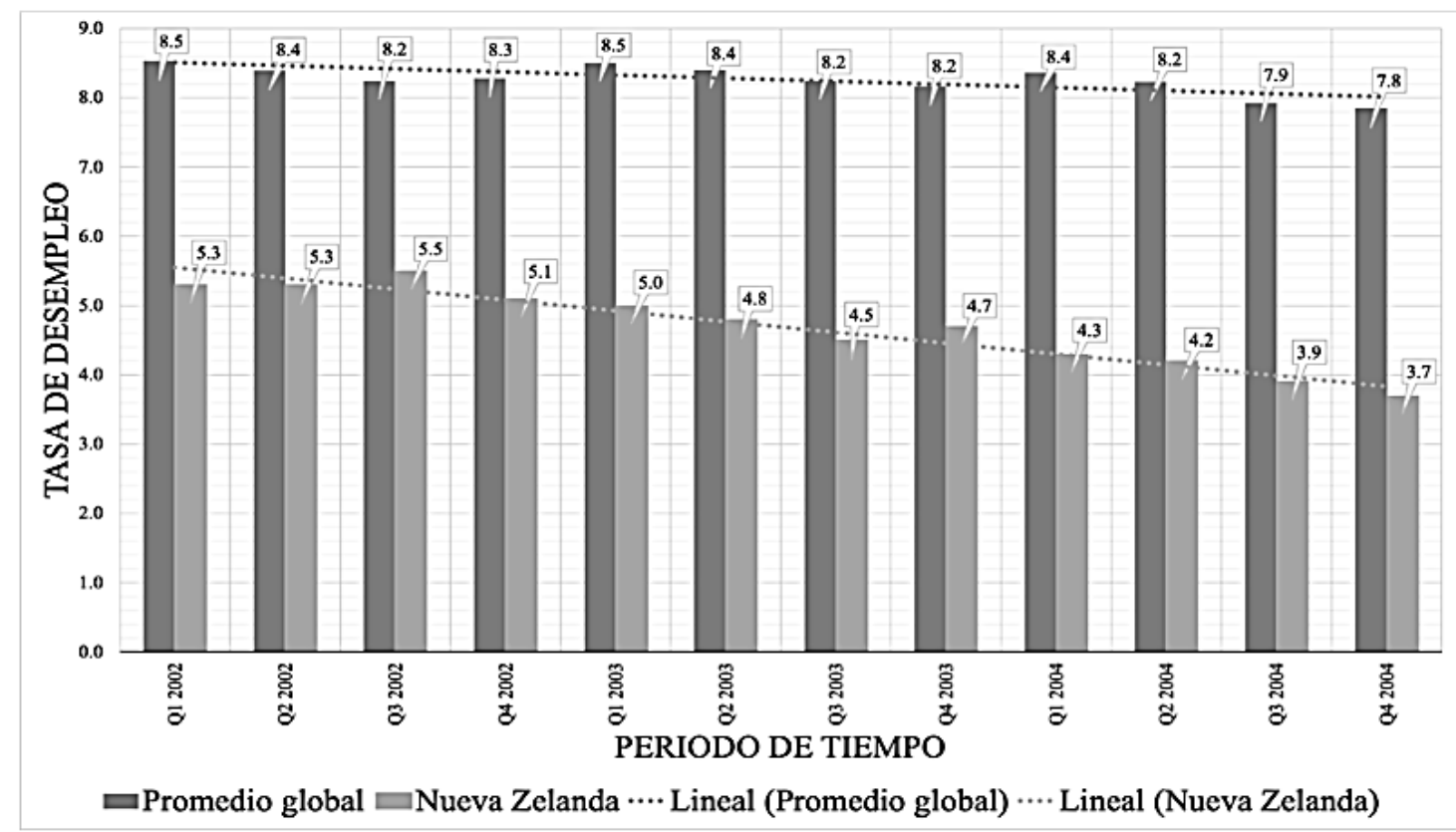

Fuente: Elaboración propia con base en Oxford Economics, Banco de Datos Económicos Globales, 2002-2004.

\subsubsection{Comportamiento del comercio internacional en el contexto del SARS.}

En la Figura 3 se observa que el promedio mundial y Nueva Zelanda presentó un comportamiento opuesto respecto a sus líneas de tendencia a lo largo del gráfico. En esos términos, se observa que el escenario neozelandés tuvo un crecimiento porcentual entre el cuarto trimestre de 2002 y el primer trimestre de 2003 de 5.20\%, lo que coincide con el brote epidémico de SARS a finales de 2002 y su propagación a principios de 2003, y muestra que las EXP en el país no se vieron afectadas en este periodo. En el Q2 de 2003 las EXP neozelandesas cayeron 6.10\% en sólo tres meses, durante el periodo previo a la contención del SARS.

Esta tendencia decreciente continuó a lo largo del resto del período analizado, alcanzando un promedio de $-3.76 \%$ para el tercer trimestre de 2004 , pero recuperándose rápidamente para finales 
del mismo año con un promedio de $8.74 \%$. Como se mencionó anteriormente, durante este período de tiempo los países industrializados se vieron afectados por factores como el SARS, que interrumpieron el buen funcionamiento de las cadenas de suministro, el comportamiento de los consumidores y el comercio en todo el mundo, lo que tuvo un impacto directo en Nueva Zelanda y sus EXP(OIT, 2004).

Ahora bien, refiriéndose al cambio porcentual de las IMP en el promedio mundial (ver Figura 4), se presentó un comportamiento similar al de las EXP para el mismo período de tiempo, con una tendencia positiva en su mayor parte y procedente de un comienzo negativo en el Q1 de 2002; Nueva Zelanda también mostró una línea de tendencia creciente. El promedio global para el valor de las IMP no presentó cambios negativos entre el cuarto trimestre de 2002 y el primer trimestre de 2003, en donde se puede observar crecimiento para ambas escalas en este período, con un incremento en IMP de $2.08 \%$ para el promedio mundial y de $2.29 \%$ para Nueva Zelanda. Por otra parte, se registró una importante caída en las IMP globales de $2.81 \%$ y de $3.01 \%$ para el caso neozelandés en el segundo trimestre de 2003, que luego se recupera en el siguiente trimestre luciendo este comportamiento hasta el Q2 de 2004, presentándose nuevamente una caída negativa en $-2.03 \%$ por las fluctuaciones del mercado.

Figura 3

\section{Cambio porcentual de las exportaciones 2002-2004 (periodo SARS)}

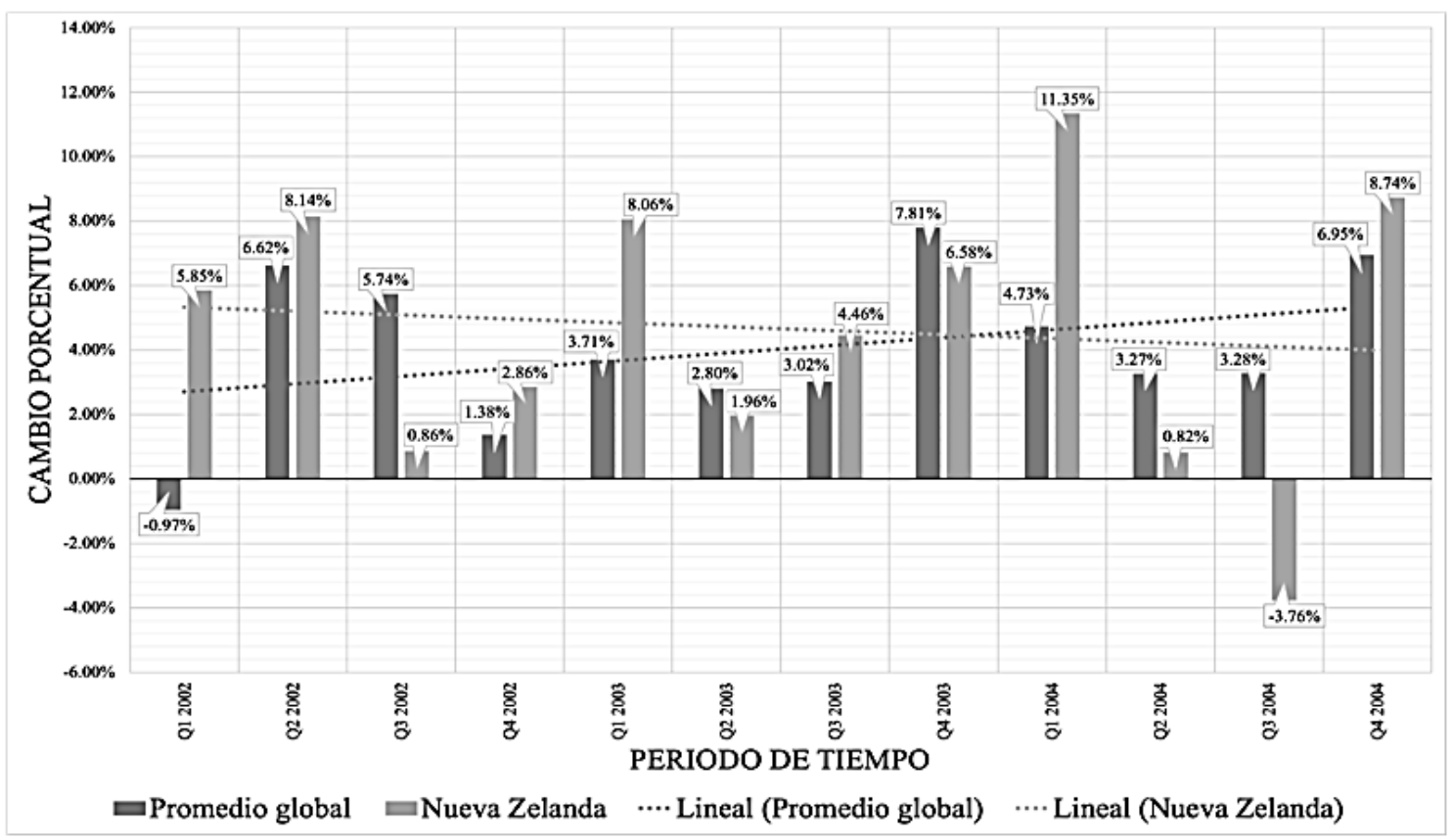

Fuente: Elaboración propia con base en Oxford Economics, Banco de Datos Económicos Globales, 2002-2004. 


\subsection{Impactos de la influenza en la salud pública global.}

La influenza se redujo rápidamente y su alcance representó más de 18,500 muertes confirmadas por laboratorios para el año 2010, sin que se llegara a un consenso sobre el promedio de la TL de esta enfermedad, debido a la dificultad para estimar la gravedad de la infección mediante el método de cálculo de la TL, y a la complejidad de la interpretación de ésta por la considerable variabilidad de las estimaciones específicas para cada edad (Wong, Kelly, Ip, Wu, Leung y Cowling, 2014); en las estimaciones se consideró un posible número desproporcionado de muertes debido a la falta de información sobre la TL en África y el sudeste asiático. El total de casos de muerte por influenza fue posiblemente quince veces mayor al número de casos confirmados por laboratorios. Se cuantificó un total de 201,200 muertes respiratorias relacionadas con la influenza a nivel mundial, además de 83,300 muertes asociadas también a la pandemia (Dawood et al., 2012).

Figura 4

\section{Cambio porcentual de las importaciones 2002-2004 (periodo SARS)}

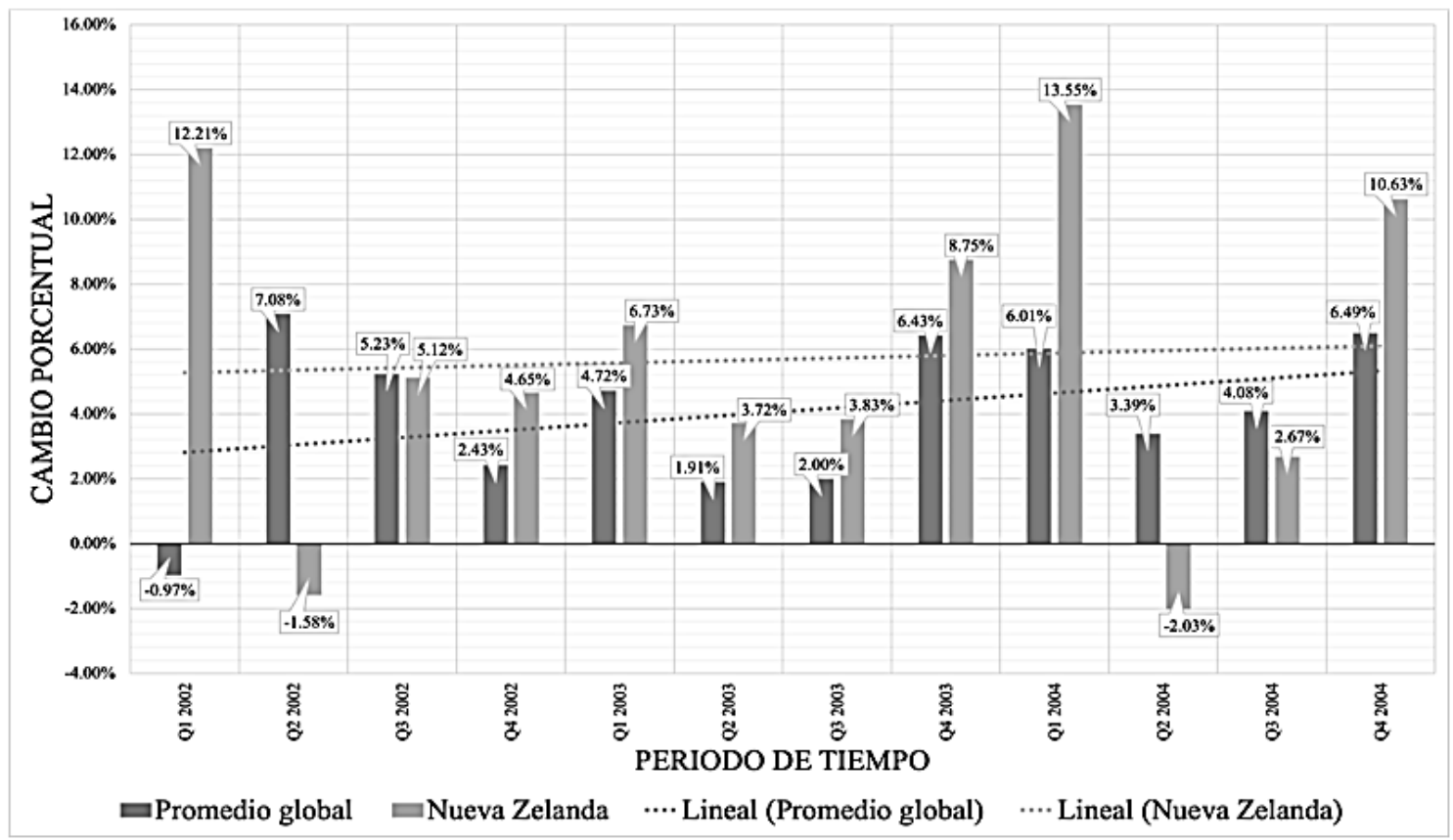

Fuente: Elaboración propia con base en Oxford Economics, Banco de Datos Económicos Globales, 2002-2004. 


\subsection{Impactos socioeconómicos globales de la influenza: el caso de Nueva Zelanda.}

\subsubsection{Comportamiento del crecimiento económico en el contexto de la influenza.}

En la Figura 5, la tasa de crecimiento del PIB real tanto para el promedio mundial como para Nueva Zelanda manifestó un comportamiento creciente en sus líneas de tendencia. En la primera escala las oscilaciones se identificaron desde $-2.92 \%$ en el Q1 de 2009 hasta llegar a $4.11 \%$ sobre el Q2 en el año 2010. Para la economía neozelandesa el rango de crecimiento fue desde $-2.28 \%$ en el Q1 de 2009 hasta llegar a 4.04\% en el Q1 de 2010. Los cambios porcentuales en ambas escalas siguieron un comportamiento similar a lo largo de los años analizados, aunque presentando diferencias después del primer trimestre de 2010.

Respecto al periodo del Q2 de 2009 al Q4 de 2010 periodo entre la aparición, propagación y control de la influenza en el mundo, se observó que el crecimiento económico comienza a presentar caídas desde el segundo trimestre de 2010, lo cual se relaciona con la pandemia de la influenza y su creciente presencia a nivel mundial para esos momentos. Por otro lado, se identificó un comportamiento negativo en los porcentajes de crecimiento del PIB real tanto para el promedio mundial como para Nueva Zelanda desde inicios de 2008 y hasta comienzos de 2009, esto se atribuye a la crisis financiera mundial generada por el mercado de bienes raíces en los Estados Unidos entre 2007 y 2008. Como la pandemia de la influenza apareció justo después del desplome del mercado interno en los Estados Unidos, las consecuencias para la economía mundial y para Nueva Zelanda en términos de crecimiento económico influyeron en los valores del periodo observado.

La economía neozelandesa experimentó un período de recesión con una contracción del PIB en términos de gasto real del $2.80 \%$ entre marzo de 2008 y junio de 2009 , con un aumento del costo de los créditos y una caída en picada de la confianza de las empresas y los consumidores, observando una recuperación en el crecimiento del PIB real después del cuarto trimestre de 2010 (New Zealand Government, 2016). De manera similar, la crisis financiera de 2007 también causó estragos en el promedio mundial puesto que 91 economías que representan dos tercios del PIB mundial en términos de paridad de poder adquisitivo (PPA) experimentaron un descenso de la producción en 2009 (Chen, Mrkaic y Nabar, 2019). 
Figura 5

\section{Tasa de crecimiento del PIB real 2008-2011 (periodo influenza) ${ }^{11}$}

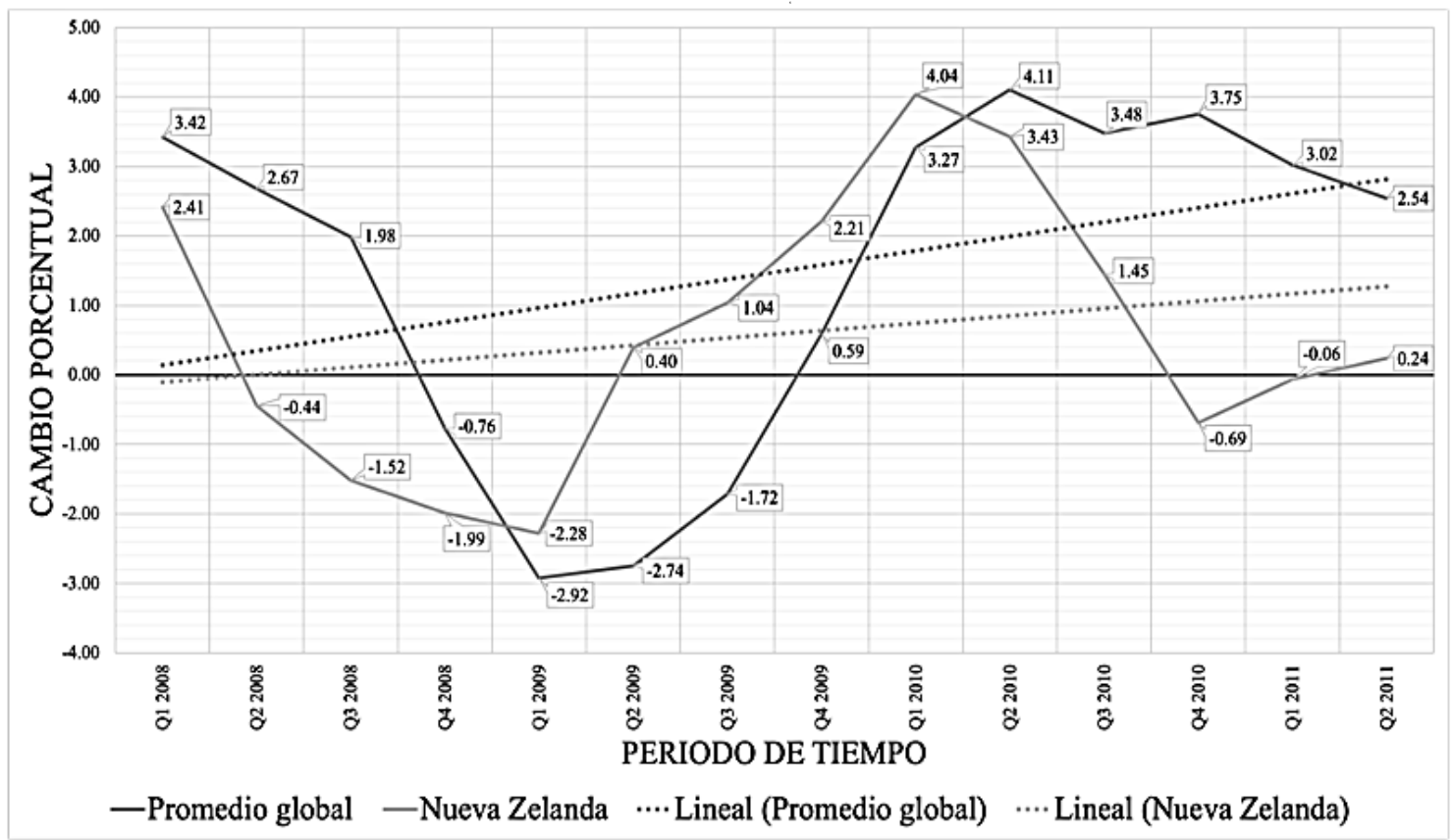

Fuente: Elaboración propia con base en Oxford Economics, Banco de Datos Económicos Globales, $2008-2011$.

\subsubsection{Comportamiento del desempleo en el contexto de la influenza.}

En la Figura 6 se muestra que la tasa de desempleo fue el indicador más afectado de los tres, ya que ambas líneas de tendencia presentaron un comportamiento creciente. El desempleo aumentó no sólo por la pandemia de la influenza entre 2009 y 2010, sino que también se vio reforzado por la recesión provocada por el desplome del mercado inmobiliario de 2007, ya que más de 210 millones de personas estaban desempleadas para entonces y las economías desarrolladas se veían gravemente afectadas (IMF, 2010).

Nueva Zelanda no se quedó atrás en cuanto al aumento de las cifras, ya que alcanzó una tasa de desempleo de aproximadamente $6.5 \%$ durante la recesión como parte de la crisis financiera mundial, también debido a un aumento de la población durante ese período. Cabe resaltar que le fue ligeramente mejor que a otros países de la OCDE, ya que aumentó 1.2\% en comparación con 3.3\%

\footnotetext{
${ }^{11}$ El PIB real global para las naciones analizadas osciló anualmente de 52,410,578.0 (miles de millones de dólares) en 2008 hasta alcanzar la cifra de 60,138,434.5 en 2011. Con una tasa de crecimiento promedio anual durante el periodo analizado de $1.0 \%$. Por su parte el PIB real anual de Nueva Zelanda registró un comportamiento de 135,613.3 (miles de millones de dólares) en 2008 hasta 167,168.4 en 2011. Presentando un crecimiento promedio anual de $1.6 \%$.
} 
de los Estados Unidos y 2.0\% del Reino Unido. Por otra parte, y aunque se vio afectada tanto por la recesión mundial como por la pandemia, el caso neozelandés expresó un aumento de casi 10\% en las matrículas para la educación terciaria para 2010 como efecto secundario de una disminución de las oportunidades de empleo (Statistics NZ, 2012).

Figura 6

Tasa de desempleo 2008-2011 (periodo influenza)

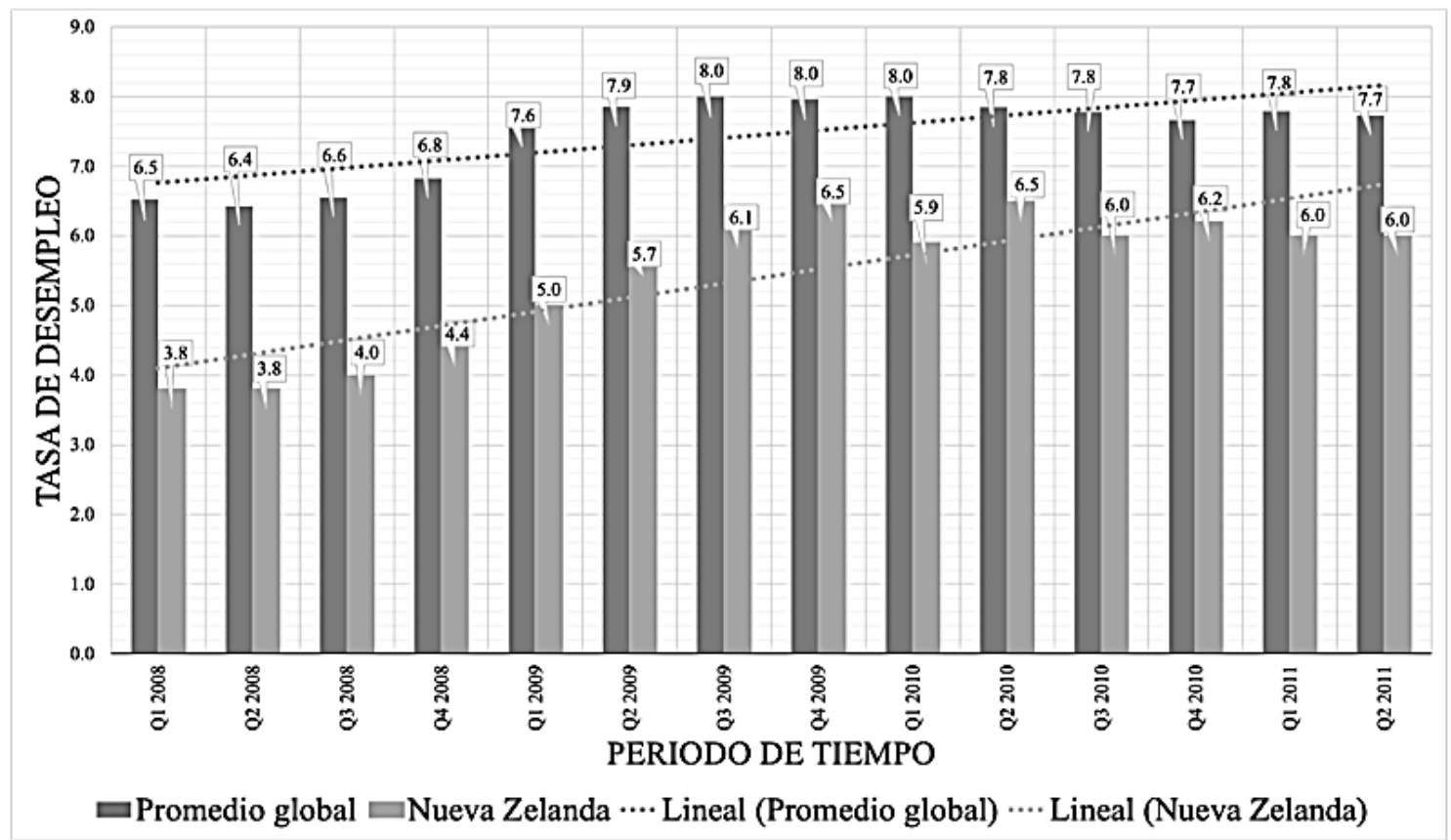

Fuente: Elaboración propia con base en Oxford Economics, Banco de Datos Económicos Globales, $2008-2011$.

\subsubsection{Comportamiento del comercio internacional en el contexto de la influenza.}

Al observar las líneas de tendencia en las EXP tanto en Nueva Zelanda como en el promedio mundial (ver Figura 7), se percibe que este indicador no se vio afectado significativamente por la pandemia o la crisis financiera mundial en cuanto a las variaciones porcentuales anuales; sin embargo, el período trimestral indicó importantes disminuciones en el comercio. El promedio mundial sufrió fuertes descensos a partir del tercer trimestre de 2008 y empeoró a finales de este mismo año alcanzando la cifra de $-17.25 \%$ y a principios de 2009 , registrando $-16.83 \%$; como consecuencia de ello, el número de operaciones comerciales importantes en los países más desarrollados y en vías de desarrollo disminuyó, ya que todas las regiones del mundo se estaban desacelerando a la vez en conjunto con las cadenas de suministro mundial, aunado a esto la escasez de financiamiento del comercio y el aumento del proteccionismo. De hecho, la carga aérea fue uno de los segmentos más 
afectados, con una disminución del 23\% en diciembre de 2008 en comparación con 2007 y con una disminución del 26\% en la región de Asia y el Pacífico, según la Asociación de Transporte Aéreo Internacional (IATA), ya que el transporte marítimo internacional disminuyó durante ese período (WTO, 2009).

Nueva Zelanda presentó un desempeño bastante similar al global, experimentó caídas en sus EXP en el Q 4 del año 2008, registrando la cantidad de -16.98\% y en 2009 sobre el Q1 presentó $11,43 \%$. Estos comportamientos se relacionan con su vínculo al mercado internacional, en donde ocurrieron periodos difíciles debido a la recesión y a una pandemia por influenza; principalmente, se atribuya a su actividad económica centrada en el sector de los servicios, complementando al mismo tiempo un sector agrícola altamente eficiente orientado a la exportación, en el que los productos básicos primarios representan más de la mitad del total de los bienes exportados, mientras que las EXP de bienes y servicios representan alrededor de un tercio del PIB respecto al gasto real (New Zealand Government, 2016). El país presentó una recuperación rápida en la segunda mitad de 2009 con repuntes en el comercio gracias a los productos lácteos, la carne, la madera, los combustibles minerales y la maquinaria (Statistics NZ, 2009).

En la Figura 8 se aprecian las líneas de tendencia para Nueva Zelanda y el promedio mundial, sugieren que las IMP se comportaron de manera muy similar a las EXP durante el período de tiempo. Las IMP globales se vieron afectadas por los acontecimientos de la crisis inmobiliaria de 2007, que se redujeron después de la segunda mitad de 2008 con una disminución de hasta $-17.94 \%$, los valores negativos continuaron hasta el segundo trimestre de 2009. Como las IMP se estaban quedando atrás junto con las EXP durante este período, regiones como el Medio Oriente y Asia cayeron un 4\% en IMP entre 2007 y 2008, mientras que Europa presentó un crecimiento negativo del 1\% en sus IMP y sectores como la industria automovilística alemana se enfrentaron a una disminución del $47 \%$ en su volumen de IMP, según la asociación de la industria alemana Verband der Automobilindustrie (WTO, 2009). 
Figura 7

\section{Cambio porcentual de las exportaciones 2008-2011 (periodo influenza)}

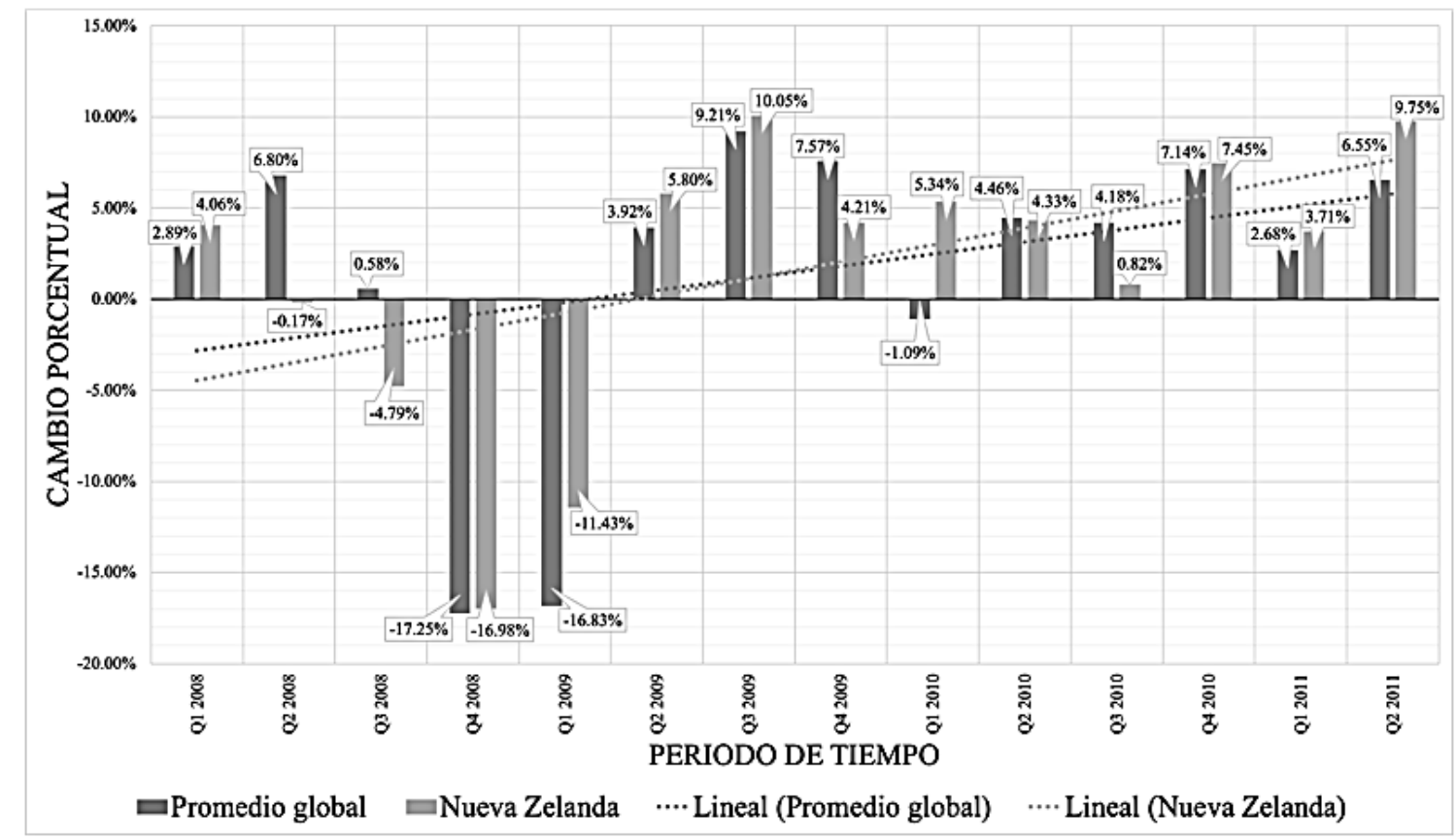

Fuente: Elaboración propia con base en Oxford Economics, Banco de Datos Económicos Globales, 2008-2011.

Nueva Zelanda presentó caídas aún más fuertes en sus IMP a partir del tercer trimestre de 2008, con una disminución que llegó hasta -6.28\% en sólo tres meses, entre el Q2 y el Q3 de ese año. Este comportamiento se agudizó en 2009 donde registró la peor caída de todo el periodo obteniendo $-20.98 \%$, esa tendencia negativa se mantuvo hasta el segundo trimestre de 2009 , alcanzando su mayor nivel en el Q4 de 2010 con 11.96\%. Este país presenta una fuerte dependencia de las EXP, lo que hace posible que una pandemia u otro tipo de disrupción en la economía asiática reduzcan significativamente el comercio, especialmente el de servicios (New Zealand Parliament, 2009). 
Figura 8

Cambio porcentual de las importaciones 2008-2011 (periodo influenza)

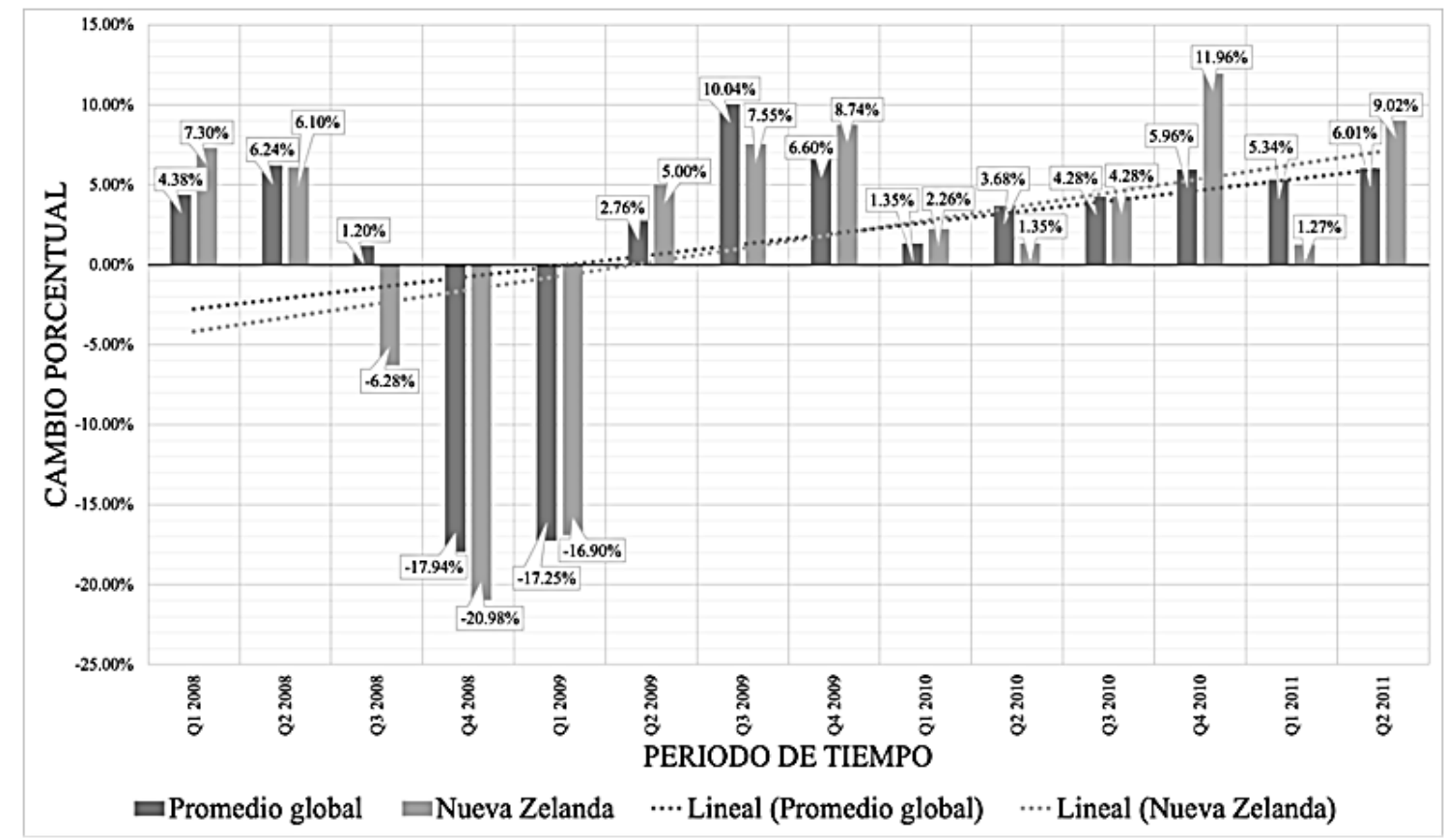

Fuente: Elaboración propia con base en Oxford Economics, Banco de Datos Económicos Globales, 2008-2011.

\subsection{Impactos del MERS en la salud pública global.}

Para efectos de esta investigación, que se centra en el análisis de pandemias y enfermedades anteriores con enfoques epidémicos de estudio similares a los del COVID-19, es importante mencionar que el MERS ${ }^{12}$ no fue clasificado por la OMS como pandemia durante su brote en 2012 y no se clasificó como tal al momento de la realización de esta investigación, aunque la OMS lo mantiene bajo vigilancia constante y se realizan actualizaciones periódicas en la página web de brotes archivados para enfermedades epidémicas y propensas a pandemias (WHO, 2020).

A finales de enero de 2020, había un total de 2,519 casos de MERS confirmados por laboratorios, con 866 muertes asociadas a éste; además, la mayoría de los casos se notificaron en Arabia Saudita, con un total de 2,121 registros validos por laboratorio que incluían 788 muertes relacionadas. Cabe resaltar, que esta enfermedad es la más mortal entre las analizadas para esta

\footnotetext{
${ }^{12}$ Según la OMS, desde 2012 sólo hay veintisiete países donde esta enfermedad ha aparecido hasta ahora: Alemania, Arabia Saudita, Argelia, Austria, Bahréin, China, Egipto, Emiratos Árabes Unidos, Filipinas, Francia, Grecia, República Islámica de Irán, Italia, Jordania, Kuwait, Líbano, Malasia, Omán, Países Bajos, Qatar, República de Corea, Reino Unido, Tailandia, Túnez, Turquía y Yemen. En cuanto a su presencia en Nueva Zelanda, no se confirmó ningún caso de MERS en el país al momento de elaborar esta investigación, según el Ministerio de Salud de Nueva Zelanda (New Zealand Government, 2020).
} 
investigación, ya que presenta una tasa de mortalidad del $34.3 \%$, y tres o cuatro personas de cada diez que mueren cuando se infectan de MERS.

\subsection{Impactos socioeconómicos globales del MERS: el caso de Nueva Zelanda.}

\subsubsection{Comportamiento del crecimiento económico en el contexto del MERS.}

El MERS no representaba un problema para aquellas economías en donde había casos confirmados. En la Figura 9 se observa que ambas líneas de tendencia abordaron un comportamiento positivo en general, el promedio mundial y el de Nueva Zelanda no sufrieron consecuencias económicas apreciables relacionadas con la enfermedad originada por el MERS ${ }^{13}$ (CDC, 2019). Los rangos del crecimiento económico en promedio global fueron de 1.70\% en el Q1 del año 2012 hasta registrar 1.95\% en el Q4 de 2014, y para el caso neozelandés, el rango fue de 3.04\% en el Q1 del año 2012 hasta registrar 4.07\% en el Q4 de 2014.

Figura 9

\section{Tasa de crecimiento del PIB real 2012-2014 (periodo MERS) ${ }^{14}$}

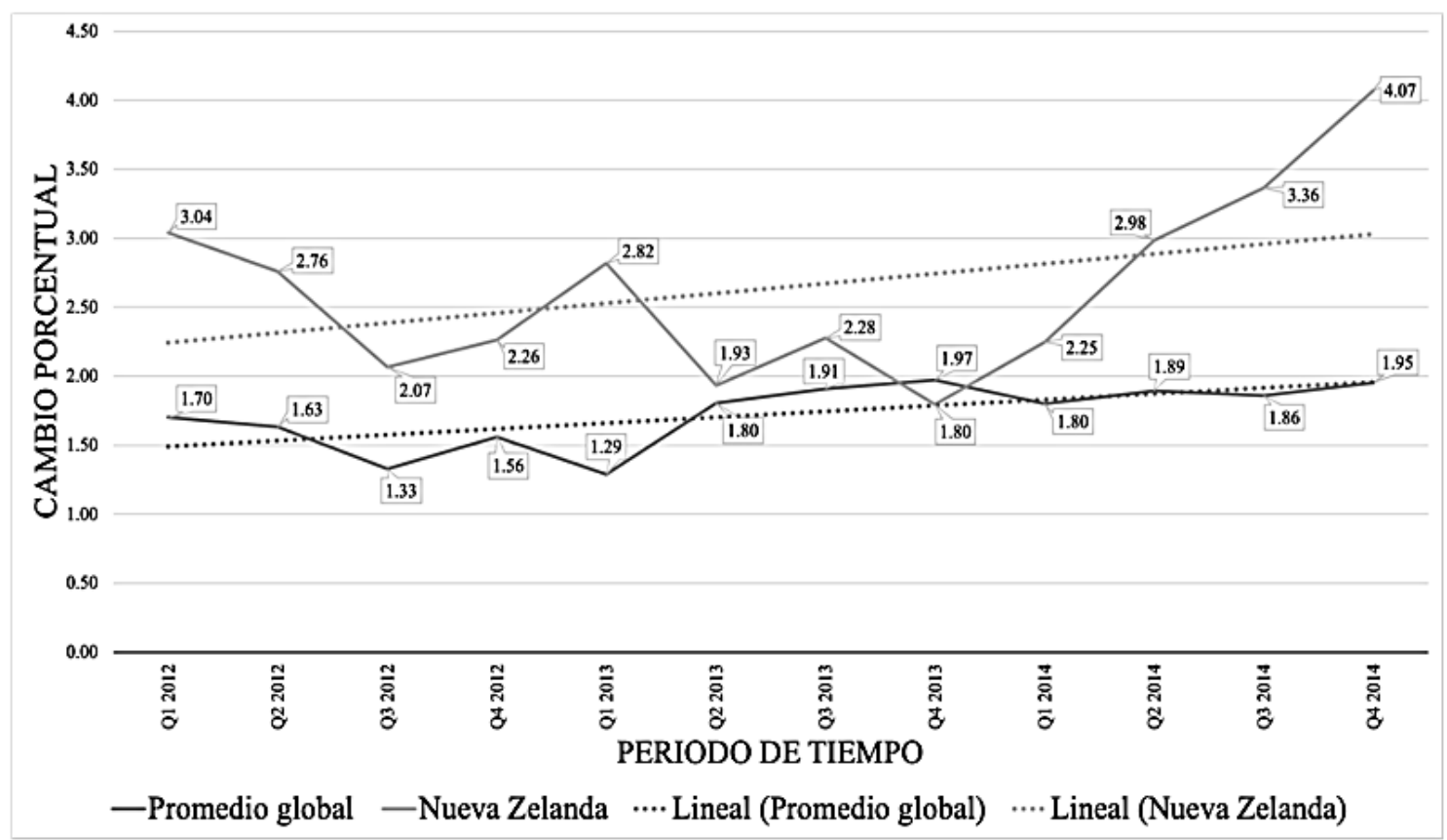

Fuente: Elaboración propia con base en Oxford Economics, Banco de Datos Económicos Globales, 2012-2014.

\footnotetext{
${ }^{13}$ Arabia Saudita fue la nación que más presentó una caída en su crecimiento económico en 2012 y 2014, pero no atribuido al MERS sino la inestable recuperación de los precios del petróleo (UN, 2012).

${ }^{14}$ El PIB real global para las naciones analizadas osciló anualmente de 61,169,172.2 (miles de millones de dólares) en 2012 hasta alcanzar la cifra de 64,399,220.4 en 2014. Con una tasa de crecimiento promedio anual durante el periodo analizado de $1.7 \%$. Por su parte el PIB real anual de Nueva Zelanda registró un comportamiento de 174,983.8 (miles de millones de dólares) en 2011 hasta 199,841.1 en 2014. Presentando un crecimiento promedio anual de $2.6 \%$.
} 
A medida que la economía se fue recuperando de las grandes dificultades como la crisis financiera de 2007-2008, el comportamiento del PIB real se fortaleció gradualmente, mostrando leves caídas entre el Q1 y el Q3 de 2012. Tras el estallido de la burbuja inmobiliaria en los Estados Unidos y la reacción en cadena que provocó una crisis económica, la mayoría de los países, tanto desarrollados como en vías de desarrollo, siguieron sufriendo los efectos de ésta, ya que se temía una posible escalada de la crisis económica en la zona euro, representando la mayor amenaza para la economía mundial durante 2012 que podría provocar una conmoción en los mercados financieros que daría lugar a una nueva llegada del riesgo en todo el mundo, provocando una contracción de la actividad económica global, según la publicación de las Naciones Unidas World Economic Situation and Prospects 2012 (UN, 2012).

Debido a lo anterior, el comportamiento del PIB durante el período 2012-2014 siguió una tendencia creciente con algunos altibajos que reflejan la vulnerabilidad de los países en desarrollo, dentro del promedio mundial, a los efectos internacionales indirectos causados por los ajustes en las políticas monetarias de los países desarrollados que también presentan altibajos en su crecimiento económico, como es el caso de Nueva Zelanda, pero también debido a sus problemas internos, la gestión incoherente de la macroeconomía, las tensiones políticas, el aumento de los riesgos financieros, etc. (UN, 2014).

Existe un país que presentó claras afectaciones debido a los brotes de MERS que no se encuentra en la Península Arábiga, este es Corea del Sur. Con la llegada de esta enfermedad al país y el comienzo de su propagación, el MERS se asocia con una pérdida de ingresos estimada en \$2,600 millones de dólares para la industria del turismo y los sectores de servicios relacionados, lo que representa el 0.2\% del PIB en 2015. Aun así, esta enfermedad no representó un impacto visible en el PIB anual de esta nación en ese año, ya que el país creció alrededor del 5\% en relación con el año anterior. También se debe mencionar, que los viajes y el turismo sólo contribuyeron al 5.1\% del PIB total, lo que hace que la disminución temporal de viajeros tenga un impacto mínimo en la economía. El mismo escenario podría tener impactos y consecuencias económicas sustancialmente mayores en un país en el que el turismo y los viajes representan un mayor porcentaje del PIB; además, que las pérdidas por turismo superaron el presupuesto del gobierno asociado a las actividades de respuesta ante el MERS (Joo, Maskery, Berro, Rotz, Lee y Brown, 2019).

\subsubsection{Comportamiento del desempleo en el contexto del MERS.}

El desempleo mantuvo un comportamiento creciente para el promedio mundial entre 2012 y 2014 en su línea de tendencia (ver Figura 10), pasando del 8.0\% en su punto más bajo al 8.4\% en su rendimiento más alto, mientras que Nueva Zelanda presentó un comportamiento decreciente durante 
todo el período con base en su línea de tendencia, mostrando sólo ligeros incrementos en el Q3 de 2012, el Q2 de 2013 y el Q4 de 2014. Según el Ministerio de Salud Neozelandés, no se ha declarado casos confirmados por laboratorios de MERS en su territorio al momento de realizar esta investigación, complicando establecer una relación entre el nivel de desempleo en la nación y la enfermedad (Ministry of Health, 2020).

A medida que la epidemia se extendió por Corea del Sur causó problemas económicos y agitación social, hasta el día en que se redujo, se descubrió que los trabajadores mayores de edad del país experimentaron un mayor desempleo y subempleo involuntarios, y una disminución de las horas de trabajo. Además, se comprobó que los trabajadores mayores de edad eran dos veces más vulnerables en este tipo de contexto, no sólo por una mayor probabilidad de enfrentarse al desempleo, sino por la necesidad de mejorar la protección médica para prevenir las condiciones que amenazaran su salud y que más tarde se convirtieran en desigualdades laborales al no ser contratados; todo ello relacionado con los efectos de una situación atípica, como son los brotes epidémicos (Lee y Cho, 2016).

Figura 10

Tasa de desempleo 2012-2014 (periodo MERS)

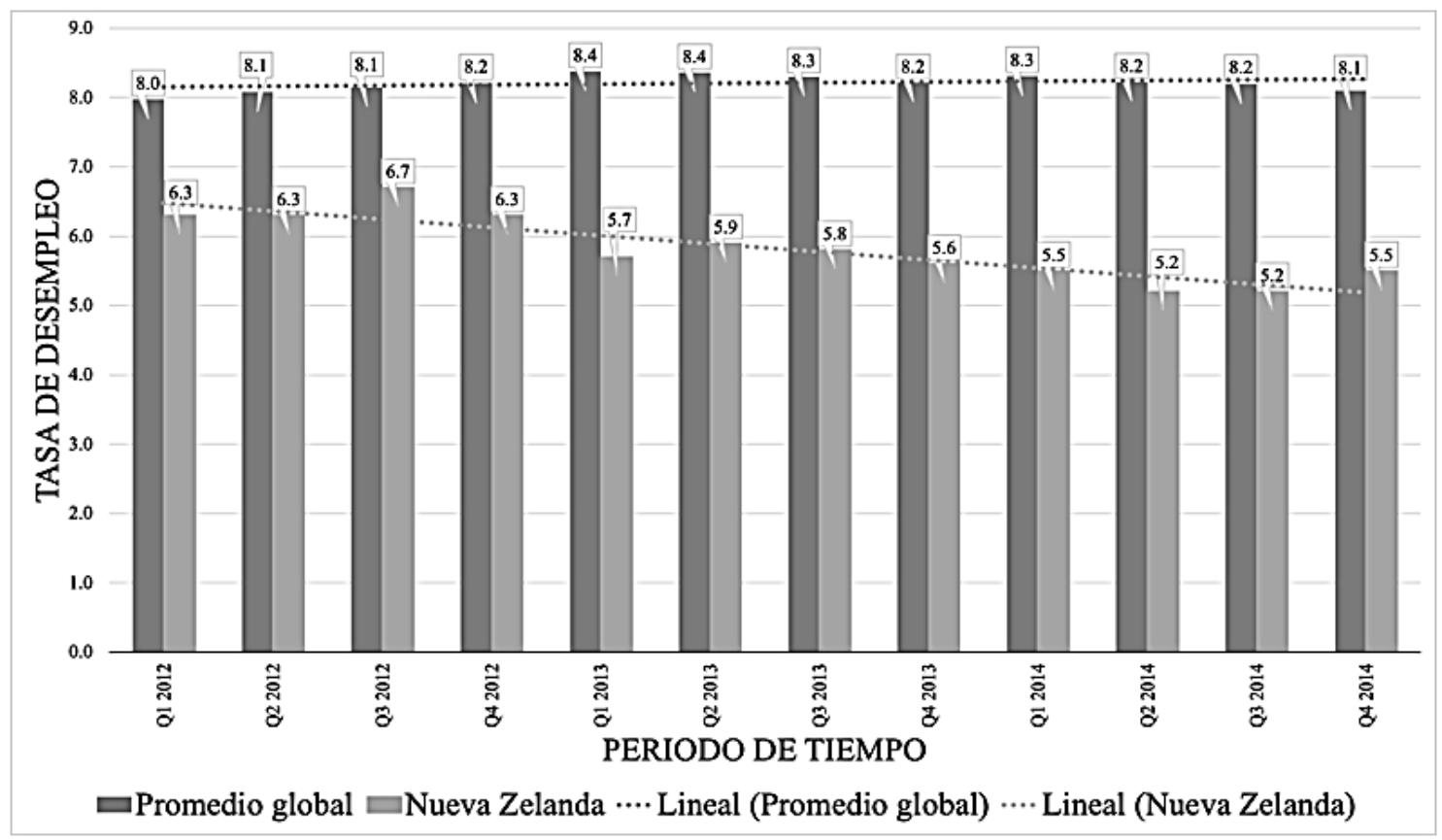

Fuente: Elaboración propia con base en Oxford Economics, Banco de Datos Económicos Globales, 2012-2014. 


\subsubsection{Comportamiento del comercio internacional en el contexto del MERS.}

El comercio internacional durante el período 2012-2014 se vio afectado por la crisis financiera al igual que el PIB, ya que es una parte importante de las actividades económicas consideradas para calcularlo. En la Figura 11, se muestra un comportamiento decreciente en la tendencia del comercio internacional con trimestres difíciles e inestables en el periodo. La cantidad negativa más alta se registró en el Q4 de 2014 con -3.07\% y los números positivos con mejor posición se ubican en el Q2 de 2014 logrando un incremento de 3.65\%. Con respecto al promedio mundial, no hay impactos severos en las operaciones comerciales de los países relacionados directamente con el MERS debido a que el número de casos registrados no fue lo suficientemente grande para afectar las operaciones de comercio exterior de manera relevante.

Por su parte, Nueva Zelanda exhibió afectaciones y comportamientos inestables en el periodo 2012-2014 tal y como lo hace el promedio mundial, explicado por factores externos además de la influencia de otros mercados y cadenas de suministro en las operaciones del país al tener un mercado abierto y sufrir las consecuencias a largo plazo de la crisis financiera de 2007. El comportamiento más bajo se registró en el Q2 de 2014 con una caída negativa de -3.92\% y el dato más positivo se identificó en el año 2013 sobre el Q4 con 10.53\%. Los cambios abruptos entre crecimiento y caídas en las EXP se debe a que los precios se moderaron y las tasas de cambio se apreciaron durante el 2012, generando caídas en la balanza de pagos; además, condiciones como el aumento en la demanda de commodities desde China en la primera mitad de 2013, la sequía en Nueva Zelanda en el verano de ese mismo año, la recuperación de la producción agrícola a finales de 2013 e inicios de 2014 y la caída de los precios en los lácteos debido al aumento de producción global de leche, y el sobreabastecimiento de esta en China jugaron un papel importante en las tasas altas y bajas en el periodo 2012-2014 (New Zealand Government, 2016). 
Figura 11

Cambio porcentual de las exportaciones 2012-2014 (periodo MERS)

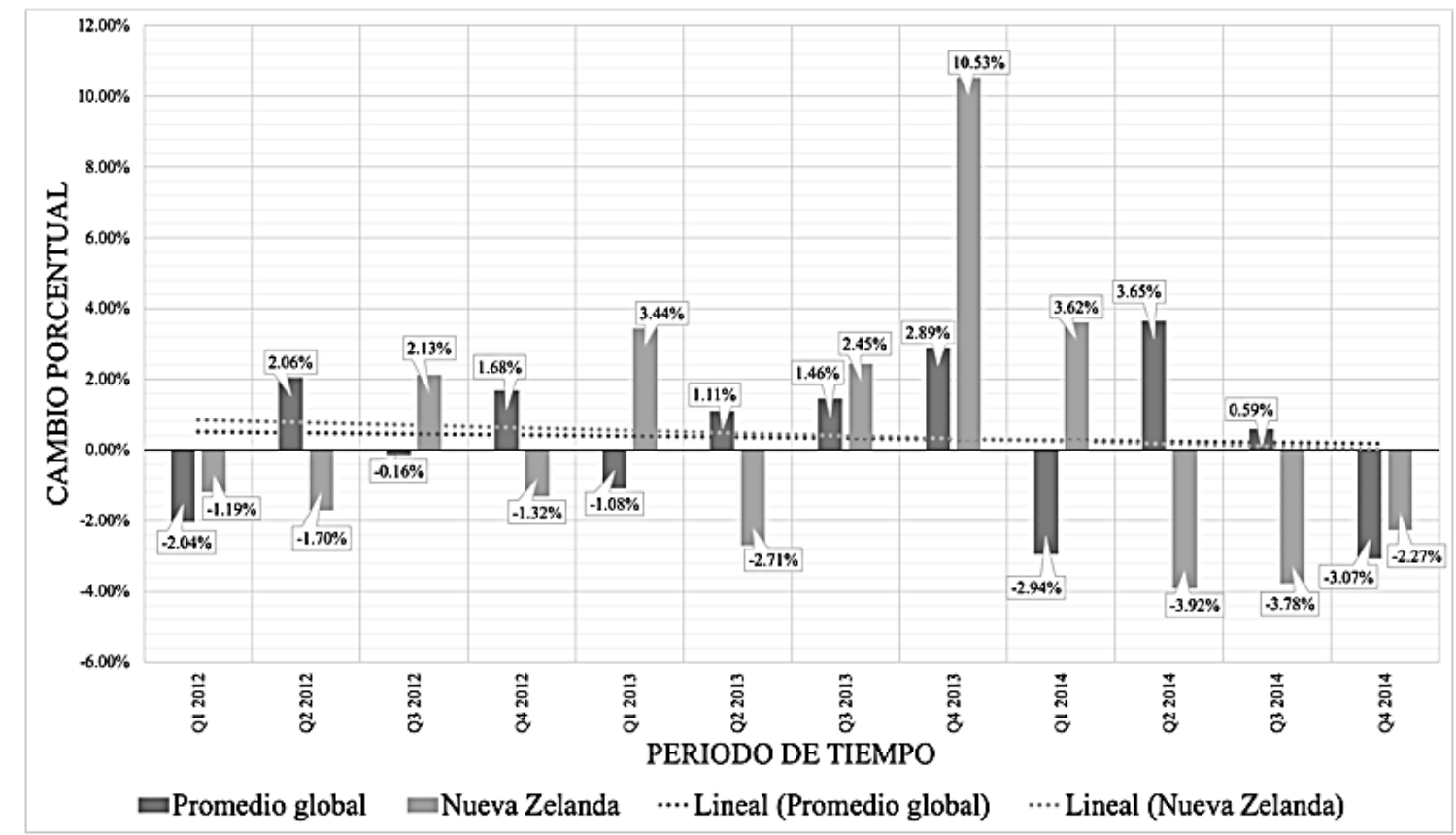

Fuente: Elaboración propia con base en Oxford Economics, Banco de Datos Económicos Globales, 2012-2014.

En la Figura 12, es notorio que ambas escalas tienen una tendencia decreciente en cuanto al comportamiento de las IMP durante este período de tiempo, siendo esto más marcado para Nueva Zelanda que para el promedio mundial. A pesar de tener trimestres particulares en los que el consumo de bienes y servicios extranjeros aumentó, hubo una tendencia decreciente en esta variable durante el período de 2012-2014, principalmente a finales del 2014. El escenario global alcanzó su registro negativo más bajo en el Q4 de 2014 con -3.59\% y la cantidad positiva más elevada se ubicó en el Q2 de 2014 alcanzando un incremento de $1.70 \%$. Al respecto del caso neozelandés, se identifica que la caída negativa más visible se presentó en el Q2 del año 2012 la cantidad fue de -4.94\%, en donde tres meses antes se había logrado el mayor incremento del periodo de análisis con 7.93\% sobre el mismo año en el Q1.

Con pocos casos confirmados fuera de Arabia Saudita y ningún caso hasta ahora en Nueva Zelanda, se puede decir que el MERS no representa un factor significativo en el comportamiento del comercio internacional durante este período. Nuevamente, los comportamientos atípicos se deben a un conjunto de factores: demanda local baja, incertidumbre en el ambiente económico global y depreciación para el dólar neozelandés a inicios de la crisis financiera de 2007, que tuvo efectos negativos a largo plazo. Además, hubo disminuciones en las IMP de combustibles minerales entre 
2013 y 2014, maquinaria y equipo eléctrico durante 2013, entre otros tipos de mercancías (New Zealand Government, 2016).

Figura 12

Cambio porcentual de las importaciones 2012-2014 (periodo MERS)

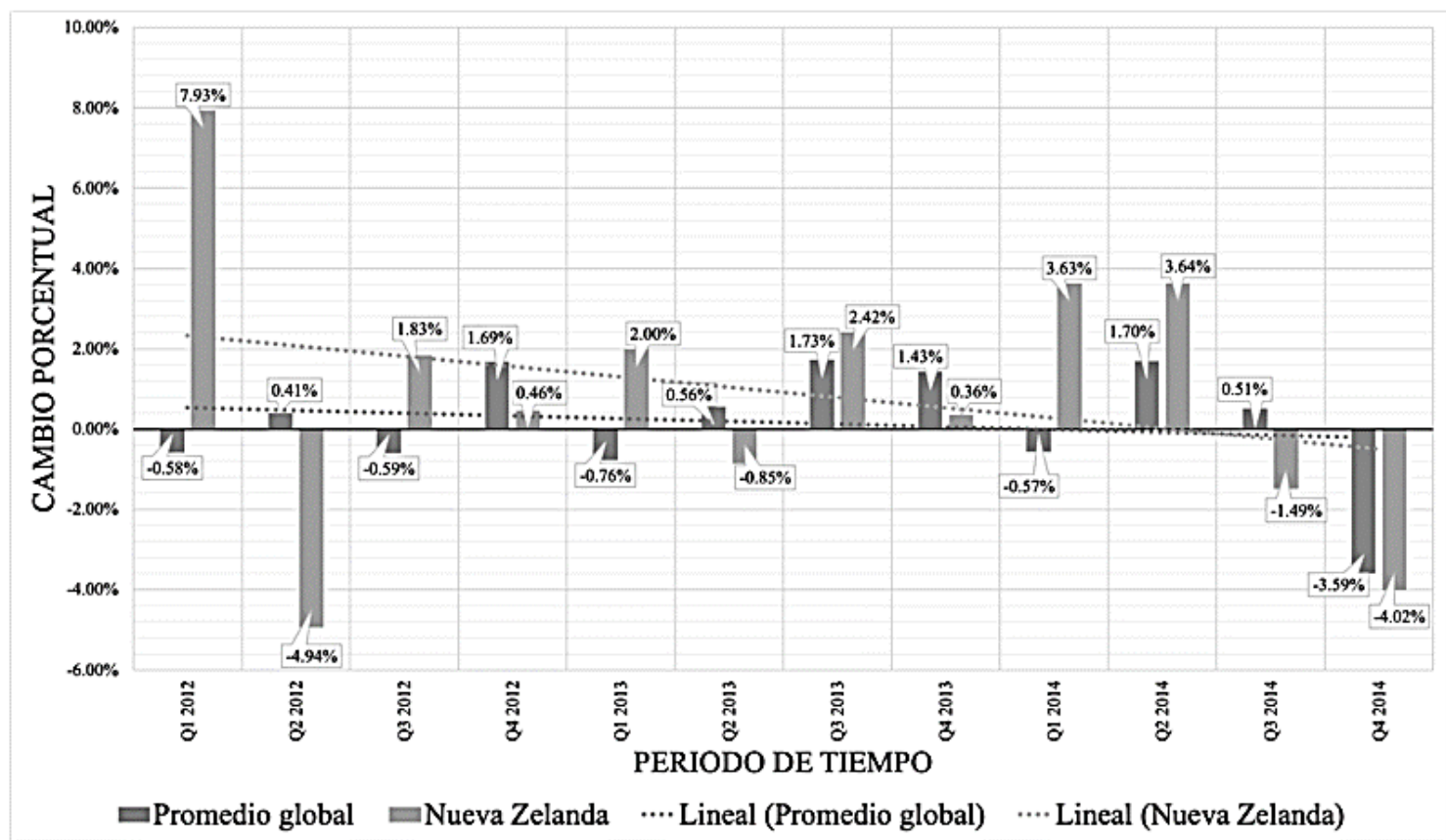

Fuente: Elaboración propia con base en Oxford Economics, Banco de Datos Económicos Globales, 2012-2014.

Aunque la relación entre la epidemia de MERS y la caída de las importaciones es mínima, se identificó que la tendencia está relacionada con la crisis financiera al igual que las EXP y, por consiguiente, el crecimiento del PIB real también lo está. Esto sucedió debido al período de inestabilidad macroeconómica y financiera en varios países en desarrollo, y a la preocupación de los grandes mercados emergentes por crecer lentamente, siendo que ambas dificultan a los exportadores de productos básicos el aumento de sus actividades comerciales (UN, 2014).

\subsection{Impactos del COVID-19 en la salud pública global.}

La cantidad de personas contagiadas por COVID-19 ${ }^{15}$ a nivel global supera los 75 millones, con 1.6 millones de muertes confirmadas (OMS, 2020). Esto impulsó una estrategia de confinamiento global para disminuir la proliferación. En referencia al porcentaje de mortalidad, actualmente existe un promedio estimado de $0.25 \%$ a $3.00 \%$ de TL debido a factores como las incertidumbres residuales

\footnotetext{
${ }^{15}$ Los virus mutan de manera natural y el SARS-CoV-2 causante de la enfermedad COVID-19 está presentando una conducta similar (WHO, 2020), es posible que los contagios aumenten.
} 
en los hospitales y en las zonas de cuidados intensivos sobre entornos de recursos escasos (Wilson, Kvalsvig, Telfar y Baker, 2020). Por otro lado, el promedio de TL en Nueva Zelanda para octubre de 2020 fue de $1.34 \%$ considerando 25 muertes y 1,864 casos confirmados (Cheng, 2020), por lo que se reportó una tasa baja dentro del promedio máximo mundial. Esto como resultado de hacer pruebas de detección y seguimiento, las características del sistema de salud y la demografía, entre otros elementos, como la adecuada gestión que tuvo la administración de su Primer Ministra Jacinda Kate Laurell Ardern (Cooke, 2020).

\subsection{Impactos socioeconómicos globales del COVID-19: el caso de Nueva Zelanda.}

\subsubsection{Comportamiento del crecimiento económico en el contexto del COVID-19.}

Los impactos económicos que esta pandemia ha mostrado hasta ahora en el mundo $\mathrm{y}$ en Nueva Zelanda ya han comenzado a ser analizados. Dos de las primeras variables afectadas por la actual pandemia son el crecimiento económico y el desempleo, siendo que un período de recesión actualmente golpea la economía mundial. En ese sentido, el PIB ha experimentado algunos de los descensos más rápidos en las proyecciones de crecimiento consensuadas entre todas las recesiones mundiales desde 1990, según el BM, con una previsión de una contracción del 5\% del PIB mundial en 2020, utilizando las ponderaciones del tipo de cambio del mercado. Esta situación, a pesar de los esfuerzos de los gobiernos por reducir el deterioro económico mediante políticas monetarias y fiscales, tendrá consecuencias especialmente graves en las economías en desarrollo y los mercados emergentes, ya que se estima que amplios sectores de la informalidad representan un tercio de su PIB y alrededor del 70\% del empleo total (BM, 2020).

Se prevé que el PIB sufrirá un descenso aún más profundo en caso de que se produzca un escenario de doble impacto con un descenso adicional por una segunda ola de infecciones con nuevos cierres en todo el mundo, que hará que se desplome un 7.6\% en 2020 para recuperarse a nivel mundial en 2021 con un 2.8\%; en cualquiera de los dos contextos, el colapso del PIB durante 2020 no podrá recuperar su tasa de crecimiento obtenida en el cuarto trimestre de 2019 hasta después de, por lo menos, dos años según las Perspectivas Económicas de la OCDE (2020). Además, se espera que Nueva Zelanda tenga una disminución general del PIB de entre $8.9 \%$ y $10 \%$ durante el 2020. Es pertinente mencionar que se espera que el desempleo de los países de la OCDE alcance un incremento entre el 9.2\% y el 10\%, comparado con un 5.4\% en 2019 (OCDE, 2020).

Conforme a los datos de OE, la tasa de crecimiento del PIB real llegó a su punto más bajo durante el trimestre de junio en el Q2 de 2020, cayendo hasta un $-11.46 \%$ de crecimiento trimestral para el promedio mundial y un $-9.31 \%$ para Nueva Zelanda. Ambos valores reflejan las condiciones 
actuales del mercado global y neozelandés frente a la pandemia por COVID-19, mostrando un período de contracción en el crecimiento y desarrollo económico (ver Figura 13).

Figura 13

Tasa de crecimiento del PIB real 2019-2022 (periodo COVID-19) ${ }^{16}$

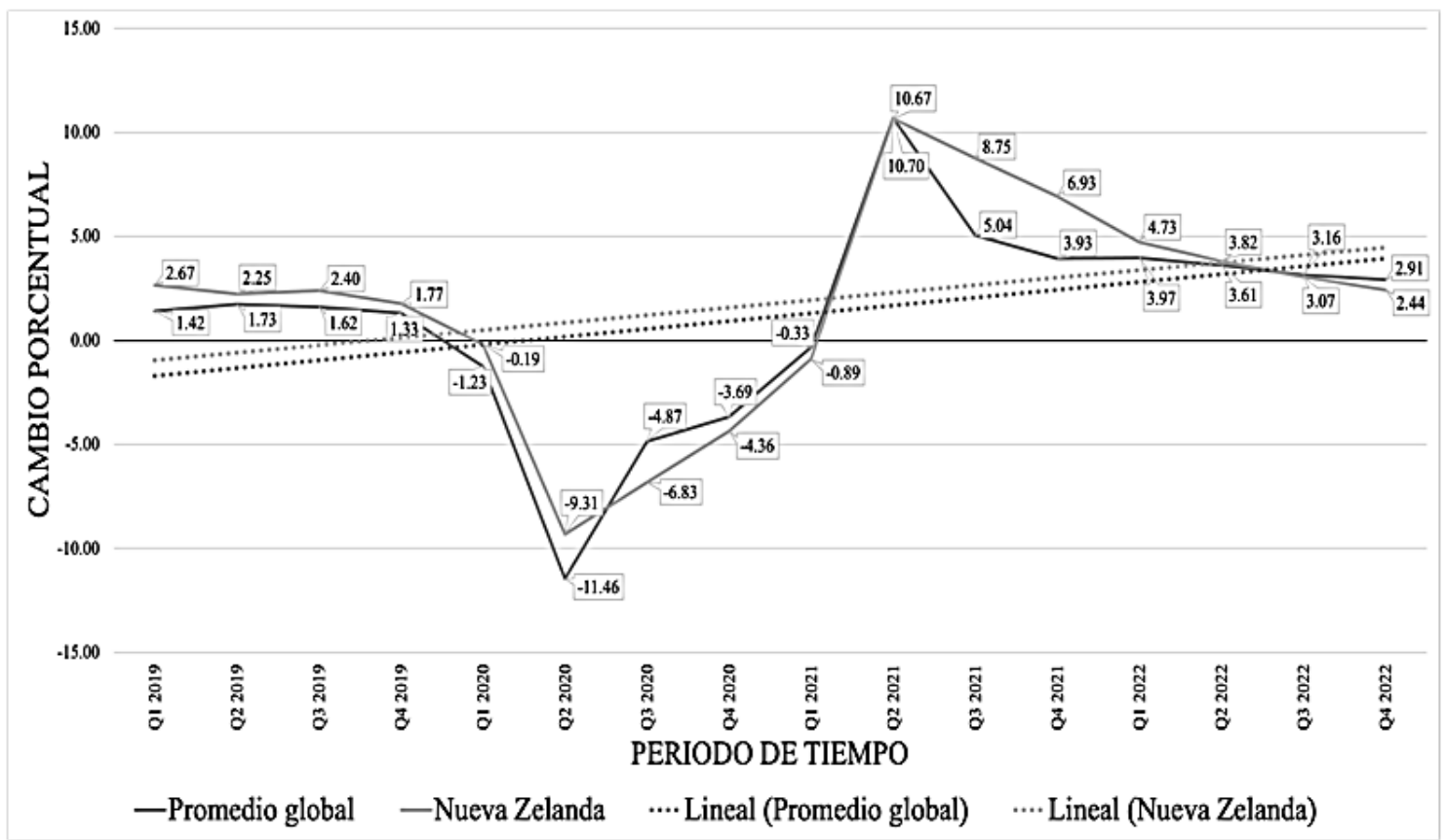

Fuente: Elaboración propia con base en Oxford Economics, Banco de Datos Económicos Globales, 2019-2022.

Las proyecciones para el año 2021 indican que la economía mundial y neozelandesa se recuperarán paulatinamente a finales del Q2 y en el Q3; el incremento más elevado para el primer caso es $10.70 \%$ y para el segundo $10.67 \%$ con oscilaciones positivas en lo que resta del año. En general, la economía global y de Nueva Zelanda, registrarán su recuperación hasta el Q1 de 2022, en donde presentan un crecimiento económico constante y por encima de lo que registraban previo a la pandemia del COVID-19.

${ }^{16}$ El PIB real global para las naciones analizadas fue de 71,782,354.7 (miles de millones de dólares) en 2019 hasta alcanzar la cifra de $68,945,427.5$ en 2020 . Con una tasa de crecimiento anual de $-4.0 \%$. Por su parte el PIB real anual de Nueva Zelanda registró un comportamiento de 205,035.1 (miles de millones de dólares) en 2019 hasta registrar 195,240.0 en 2020. Presentando una tasa de crecimiento anual de $-4.8 \%$. Estos comportamientos negativos en el PIB real se atribuyen a la pandemia del COVID-19. 


\subsubsection{Comportamiento del desempleo en el contexto del COVID-19.}

El desempleo, es parte de las variables afectadas por la actual pandemia, mostrando aumentos sin precedentes, ya que en algunos países se trabajaron hasta diez veces menos horas en comparación con los primeros meses de la crisis financiera de 2008, según la Perspectiva de Empleo de la OCDE (2020). Además, se espera que el desempleo sea elevado en 2021 y los países miembros de la OCDE prevén un $12.6 \%$ para el cuarto trimestre de 2020 en caso de que se produzca un escenario de doble impacto, comenzando el primer trimestre de 2021 con una tasa de desempleo del $11.1 \%$, siendo los jóvenes y las mujeres los que corren un gran riesgo de desempleo y pobreza, ya que generalmente tienen trabajos menos seguros y no cualificados, teniendo mayor representación en las industrias más afectadas por la crisis como el turismo y los restaurantes (OCDE, 2020).

Nueva Zelanda se ha recuperado lentamente del aumento del desempleo pasando del $4.2 \%$ en el primer trimestre de 2020 al 4.0\% en el segundo trimestre de 2020 (ver Figura 14); sin embargo, la subutilización aumentó al 12\%, así como el número de personas que no forman parte de la fuerza laboral, esto significa que menos personas que no tienen empleo buscan activamente conseguirlo, explicando el aumento de $10.4 \%$ a $12 \%$ en la subtilización mencionada anteriormente (Stats NZ, 2020). Cabe mencionar, que se muestran líneas de tendencia creciente en el periodo analizado, con el promedio mundial manteniéndose por encima del 9.0\% y Nueva Zelanda sobre el $4.7 \%$ para inicios del 2021, manteniendo altos niveles de desempleo hasta finales de 2022.

Considerando las condiciones actuales del desempleo en el mundo y los efectos a largo plazo de éste a raíz de una pandemia que no ha terminado, es posible ver que la tasa de desempleo a nivel mundial continuará por encima del $9.0 \%$ durante el resto del 2020, sólo para disminuir progresivamente desde los primeros tres meses del año del 2021. Por otra parte, Nueva Zelanda sufre un aumento de su tasa de desempleo alcanzando un $4.7 \%$ para finales del 2020, y manteniendo ese nivel durante la mayor parte de 2021, con una ligera disminución durante 2022. 
Figura 14

Tasa de desempleo 2019-2022 (periodo COVID-19)

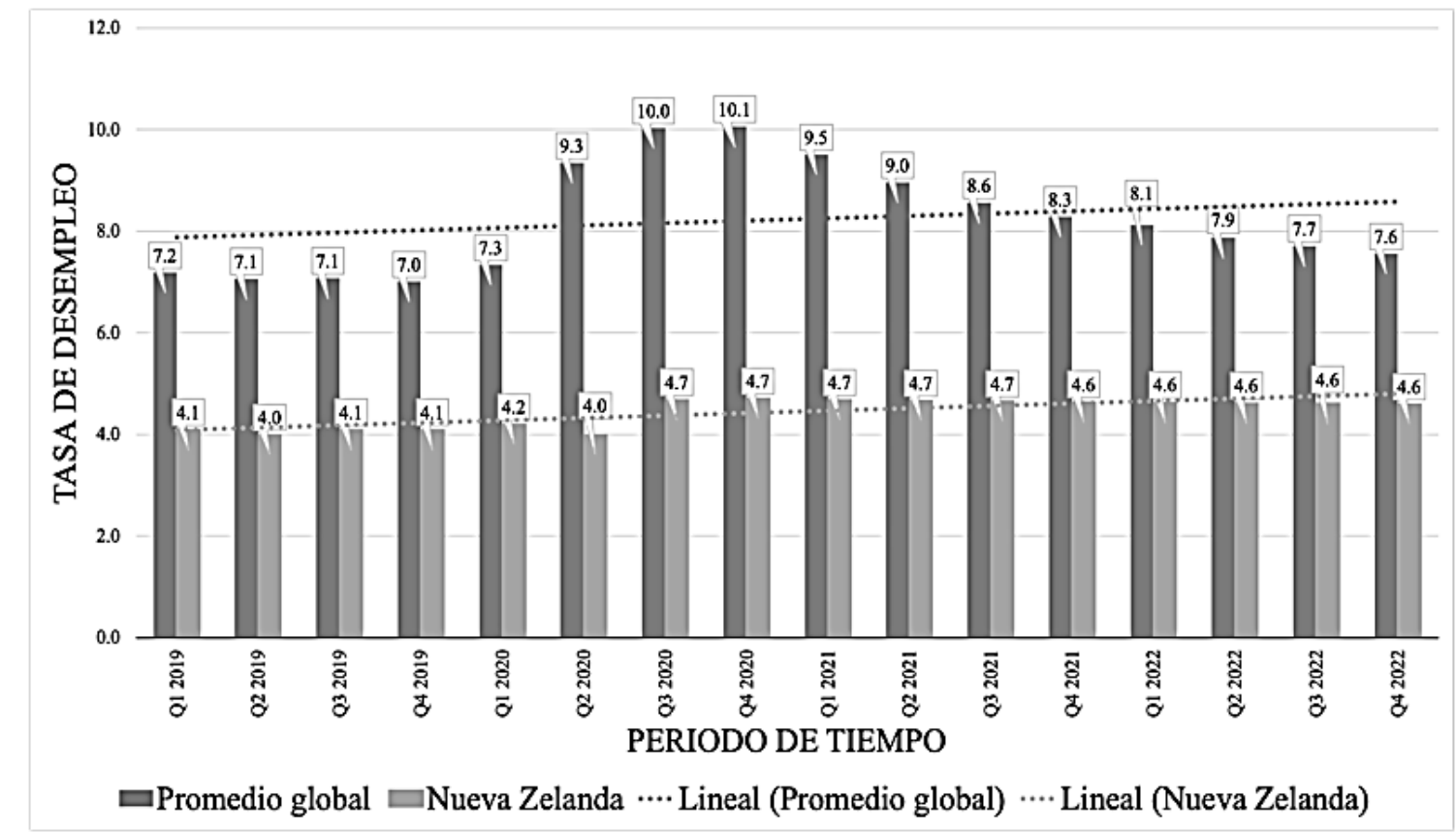

Fuente: Elaboración propia con base en Oxford Economics, Banco de Datos Económicos Globales, $2019-2022$.

\subsubsection{Comportamiento del comercio internacional en el contexto del COVID-19.}

Las EXP e IMP se comportan de una manera similar en el 2019 y 2020, con ligeras variaciones, las caídas negativas más bajas se presentaron cuando la pandemia por COVID-19 se expandía por el mundo. En otras palabras, los comportamientos más negativos de las EXP y IMP se registraron en el Q1 y Q2 del 2020. Para la escala global en términos de EXP la cantidad más baja que se identificó fue de $-15.38 \%$ y para Nueva Zelanda $-17.27 \%$. En cuanto a las IMP globales, la disminución más visible fue de $-18.08 \%$ y en el caso neozelandés $-25.11 \%$ (ver Figuras 15 y 16 ).

Las proyecciones para 2021 y 2022 tienen un gran parecido en sus líneas de tendencia para ambas escalas en su distribución de EXP e IMP entre cuartiles, mejorando lentamente a partir del Q2 de 2021 y recuperándose en el Q2 de 2022, con un comportamiento estable para lo que resta del año. En síntesis, el comercio internacional y las cadenas de suministro de todo el mundo se están viendo afectadas ante la pandemia por COVID-19 y se prevé una recuperación para mediados del 2021, la cual se mantendrá en el 2022. 
Figura 15

Cambio porcentual de las exportaciones 2019-2022 (periodo COVID-19)

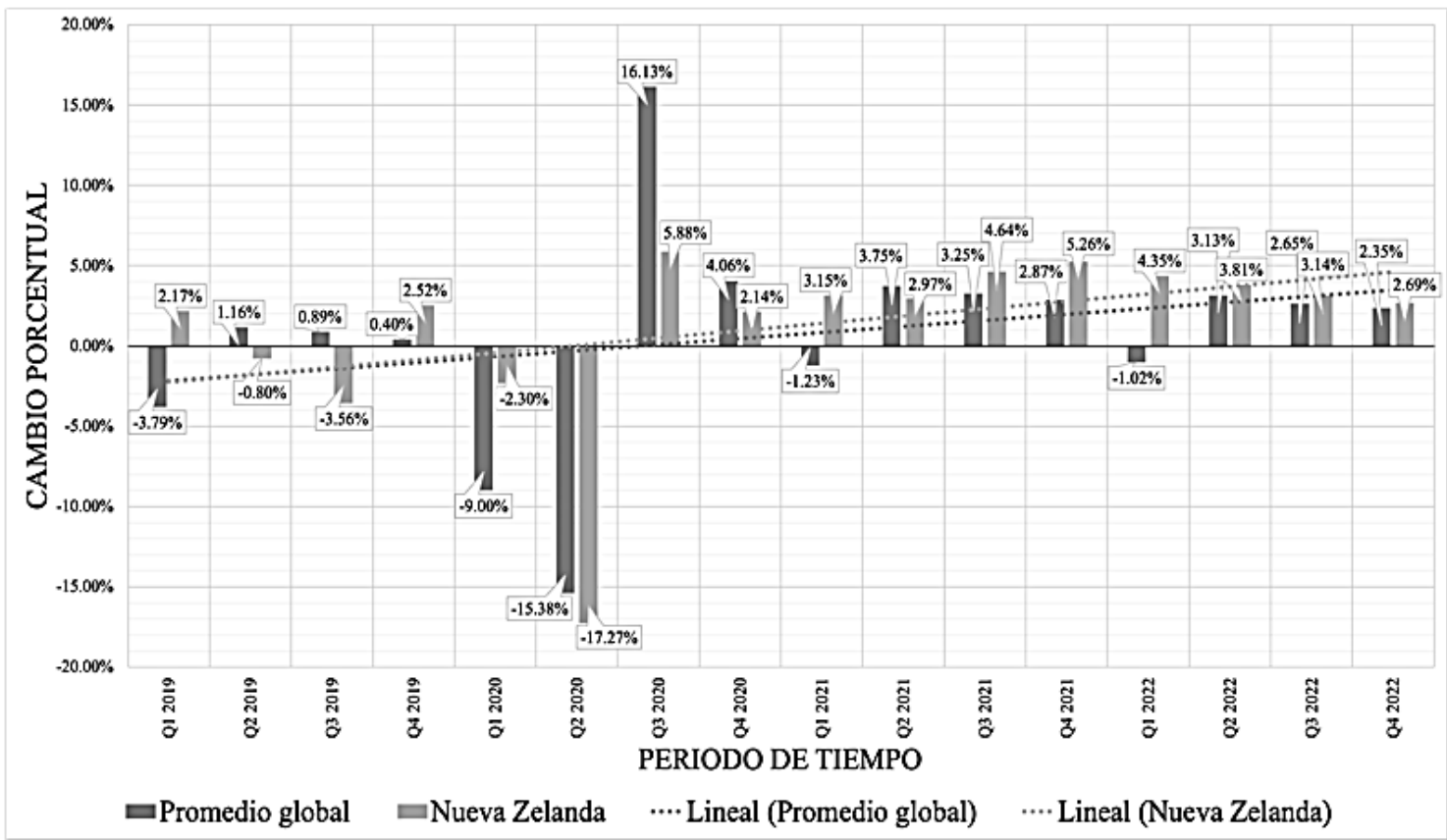

Fuente: Elaboración propia con base en Oxford Economics, Banco de Datos Económicos Globales, 2019-2022.

Figura 16

Cambio porcentual de las importaciones 2019-2022 (periodo COVID-19)

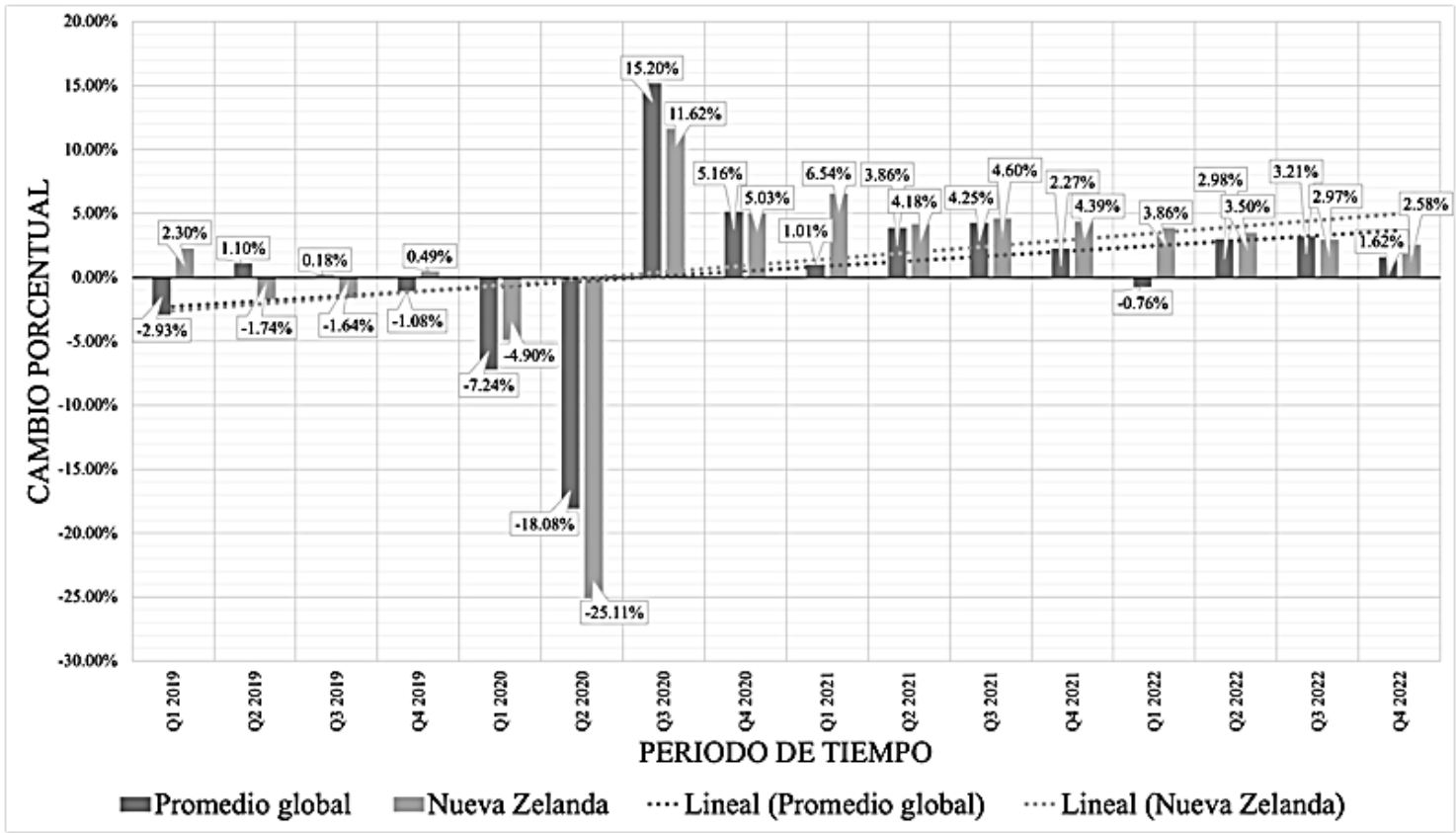

Fuente: Elaboración propia con base en Oxford Economics, Banco de Datos Económicos Globales, 2019-2022. 
Bajo el contexto mundial frente a la actual pandemia por COVID-19 se han realizado diversos estudios para identificar cómo se ha gestionado el riesgo de los brotes y sus impactos socioeconómicos. En esa orientación, la investigación realizada en conjunto por el Management Center Innsbruck de Austria, la Universidad de Newcastle en Australia y la Universidad de Bologna en Italia, identificó que Grecia, Islandia, Nueva Zelanda y Singapur lograron controlar la pandemia en una fase temprana en relación al número de casos positivos, aunque poseían perfiles demográficos, epidémicos y socioeconómicos distintos entre sí (Fouda, Mahmoudi, Moy y Paolucci, 2020).

Esto se logró gracias al manejo de la sobrecarga de sus sistemas de salud y disminución de su TL de COVID-19, así como por las intervenciones tempranas en el control de la enfermedad, y la generación y fomento de numerosos estímulos y medidas de alivio económico. Estos descubrimientos llevaron a la conclusión de que las intervenciones tempranas, proactivas y estrictas en conjunto con la experiencia en el manejo de enfermedades comunitarias y la evolución de estrategias para realizar pruebas de infección fueron clave en el manejo de la actual pandemia en los cuatro países (Fouda, Mahmoudi, Moy y Paolucci, 2020).

Por su parte, la Universidad de Newcastle en Australia realizó una investigación sobre Corea del Sur analizando sus políticas e innovaciones para combatir el COVID-19. En ésta se logró concluir que la ejecución agilizada de enmiendas en artículos legislativos para proteger la salud de su fuerza laboral resultó en el contagio del virus en únicamente 10 profesionales de la salud cuidando a pacientes con COVID-19; esto, conllevó a una pérdida mínima en capital humano y permitió al gobierno surcoreano redirigir su fuerza laboral médica ya existente a áreas que lo necesitaran. Además, las estrategias de cuarentena implementadas propiciaron la poca necesidad de mandar a todo el país a un cierre económico indefinido (Fouda, Mahmoudi, Moy y Paolucci, 2020).

Lo anterior fue posible gracias al trabajo en conjunto de los Centros para Prevención y Control de Enfermedades de Corea (KCDC) y de los expertos en la salud, quienes desarrollaron innovaciones clave en el país: rastreo completo de contactos y pruebas rápidas con respuesta de 12 horas y sistemas de monitoreo de movimientos a 10 minutos, transparencia en la publicación y acceso a los datos del rastreo completo de contactos al público mediante una base de datos central, métodos de prueba drive-through y walk-through, y finalmente un índice de gravedad de los pacientes y la implementación de centros comunitarios para el tratamiento de aislamiento. Con este conjunto de medidas y agilidad gubernamental, Corea del Sur pasó de ser el cuarto país con más casos confirmados en el mundo en marzo a el número 76 para el mes de agosto (Doowon y Bobae, 2020).

En términos de desempleo, el Urban Institute de los Estados Unidos desarrolló un análisis de los efectos de la pandemia por COVID-19 en el país a través del Coronavirus Tracking Survey, encuesta aplicada a una muestra poblacional de 4,352 mayores de edad que habían tomado el Health 
Reform Monitoring Survey (HRMS) entre marzo y abril del 2020; con esto, obtuvieron resultados que indican lo siguiente: más de dos de cada cinco adultos reportaron pérdidas de empleo o ingresos debido al impacto económico de la pandemia; además, la muestra de adultos trabajando decayó a 65.6\% para mayo comparado con 68.1\% en marzo/abril (Acs y Karpman, 2020).

Asimismo, un estudio elaborado por el National Bureau of Economic Research en Massachusetts, determinó que un estimado de 20 millones de empleos se perdieron para el 6 de abril de 2020 en este país, siendo muchos más que los perdidos durante toda la Recesión de Estados Unidos entre 2007 y 2009; además, se vio que el número de personas buscando empleo activamente fue muy bajo puesto que el desempleo sólo se elevó $2 \%$ cuando se esperaba un aumento del $12.2 \%$ debido a la pérdida de millones de empleos en la economía estadounidense, con ello se comprende que el porcentaje de personas que están buscando un nuevo empleo activamente es mucho menor al de aquellas que se quedaron sin uno. Aunado a esto, se identificó que la participación en la fuerza laboral decayó 7\% durante la pandemia por COVID-19 (Coibion, Gorodnichenko y Weber, 2020).

Respecto al crecimiento económico, se planteó un estudio por el Board of Governors del Sistema de la Reserva Federal de Estados Unidos, la Reserva Federal del Banco de Nueva York y la Sloan School of Management del Massachusetts Institute of Technology (MIT) para identificar si las intervenciones no farmacéuticas (INF) como el distanciamiento social, el aislamiento, la cuarentena, entre otros, tienen efectos adversos en la economía. Para esto, usaron una variación de tiempo e intensidad de las INF utilizadas en los Estados Unidos durante la pandemia de influenza de 1918 para examinar su impacto económico; se llegó a la conclusión de que los efectos económicos adversos se presentaron de manera similar tanto en ciudades con INF estrictas como en aquellas más indulgentes en sus medidas y, siendo que la pandemia por sí misma está asociada con disrupciones económicas en el corto plazo, no se encontró evidencia de que las INF generan impactos económicos negativos.

En todo caso, las INF mostraron estar asociadas con mejores resultados para la economía en el mediano plazo, ya que pueden ayudar a reducir la transmisión de enfermedades sin necesariamente deteriorar la actividad económica. Aun así, las INF limitan las interacciones sociales y, por ende, las actividades económicas ligadas a éstas. Una pandemia como tal genera impactos en el crecimiento y desarrollo económico de un país o región aún en ausencia de INF, porque los hogares reducen su consumo de bienes y servicios en conjunto con su oferta laboral para disminuir el riesgo de infección, así como también las empresas reducen su inversión en el mercado por los altos niveles de incertidumbre. Aunque el efecto directo de las INF es una disminución en la actividad económica, éstas también mitigan el impacto de la pandemia al contenerla y, a su vez, aminoran las disrupciones económicas ligadas a la misma (Correia, Luck y Verner, 2020). 
En la búsqueda de posibles alternativas que contemplen los esfuerzos ya existentes tanto en la salud pública como en el sector económico para amortiguar los efectos socioeconómicos adversos, algunos autores como Van Parijs (1992), Villarreal (2020) y Yánez (2020) plantean la consideración de un ingreso básico universal, entendiéndolo como un monto económico que se entrega a la población más vulnerable y no requiere de criterios de desempeño laboral presente o pasado. Esto fomentaría que las personas tengan dinero y se impulse el consumo de bienes y servicios para que la demanda agregada no caiga. Esta propuesta parece utópica y sesgada si se le considera como la panacea que permitirá la completa recuperación de la economía en el mundo, puesto que depende de diversos factores externos e internos, y no puede ser aplicada de la misma manera en las diversas regiones del planeta, ni tampoco de forma instantánea y generalizada.

Hablar de la posibilidad de instaurar un ingreso básico universal requiere de un esfuerzo titánico en lo que respecta a la formulación de estrategias que permitan la introducción de esta medida. Profundizando en esto, se habla concretamente de cambiar los paradigmas de lo que se entiende por libertad e igualdad para todos los seres humanos, cuestionando si realmente se puede ser libre e igual sólo por los derechos políticos o sociales sin incorporar los derechos económicos; estos últimos siendo los que plantean la condición de que los seres humanos se construyen con esas características no sólo por la iniciativa, sino también por crear oportunidades de posibilidad (Yánez, 2020).

Estas oportunidades se refieren a gozar de derechos económicos que permitan su bienestar, por ello, el ingreso básico universal es más que una política pública o fiscal de crecimiento económico a mediano y largo plazo, se formula como una alternativa para repensar los estados sociales de bienestar que conocemos hoy en día, y para disminuir la exclusión como la pobreza en grupos vulnerables, todo esto considerando la situación atípica que se vive hoy con una pandemia que aún no termina (Villareal, 2020).

A su vez, otra propuesta que surge para disminuir los impactos socioeconómicos del COVID19 son los esquemas de retención de empleo, éstos son estrategias gubernamentales que ayudan a los empleadores a cubrir los costos del personal por diversos motivos mediante subvenciones del salario de un empleado con el objetivo de evitar despidos (Local Government Association, 2020). El Reino Unido, Australia y Nueva Zelanda ya los han aplicado, financiando más de 30 millones de empleos, reduciendo el riesgo de cese como resultado de problemas de liquidez y previniendo así un aumento del desempleo (OCDE, 2020).

Con la implementación de los protocolos de salud pública mencionados anteriormente, el ingreso básico universal y la retención de empleos se podría avanzar en la generación de políticas públicas que incluyan estímulos y medidas para controlar la pandemia e impulsar la reactivacióneconómica mundial. 


\section{$\rightarrow$ 5. Conclusiones.}

- En cuestiones de salud pública global, se indica que la TL más elevada la posee el MERS, siendo éste el que ha causado más muertes a nivel global en función de los contagios registrados, ya que 4 de cada 10 personas que se infectan mueren. Por su parte, el COVID19 ha generado el mayor número de contagios, superando los 75 millones en el planeta, ocasionando 1.6 millones de muertes. La influenza ocasionó que 201,200 personas perdieran la vida y el SARS 774.

- Con la información recabada para los diferentes periodos de análisis, se identificó que los virus y sus brotes epidémicos tienen efectos adversos en el crecimiento y desarrollo económico global según su magnitud y alcance. Los datos socioeconómicos, indican que estas patologías afectaron directa o indirectamente a todas las variables elegidas para esta investigación (crecimiento económico, desempleo y comercio internacional).

- La tasa de crecimiento porcentual del PIB real se ve afectada de manera inmediata trimestralmente tras el surgimiento de brotes epidémicos y las repercusiones son notorias en el mediano plazo. La tasa de desempleo es la más afectada causando efectos multiplicadores a corto y largo plazo que disminuyen el ingreso, el consumo, la inversión y desestabilizan el crecimiento y desarrollo económico. El comercio internacional y las cadenas de suministro de todo el mundo sufren fuertes afectaciones en el corto plazo, causando comportamientos atípicos en las EXP e IMP, pero éstas se recuperan rápidamente y no muestran grandes afectaciones en el largo plazo a menos que haya otros factores externos que propicien una caída en conjunto.

- Los brotes epidémicos que más impactaron socioeconómicamente en Nueva Zelanda fueron la influenza (2008-2011) y el MERS (2012-2014). En particular, el primero, ya que se presentó en el contexto de la crisis económica del 2008-2009 a nivel global. En cuanto al SARS (2002-2004) y al COVID-19 (2019-2020), los impactos fueron mínimos, porque el gobierno aplicó las medidas necesarias para contrarrestar a los virus y gestionar el riesgo de contagios.

- Nueva Zelanda ha sido una de las naciones menos perjudicadas a nivel global por los distintos virus y sus respectivos brotes epidémicos analizados, esto se explica en gran medida porque su población y territorio son pequeños, con un crecimiento y desarrollo 
económico constante y los habitantes poseen alto grado de educación. Estos factores impulsaron la creación temprana de las medidas necesarias para establecer los protocolos de salud pública.

- Al respecto de las proyecciones para cada una de las variables estudiadas se identificó que a nivel global los primeros meses de 2021 presentarán un comportamiento lento de recuperación socioeconómica y a partir del Q3 (julio-septiembre) la expansión se tornará creciente. En el año 2022 las tendencias positivas empezarán a ser constantes en el Q2 (abril-junio) en la medida que la pandemia sea controlada con las vacunas. En el caso de Nueva Zelanda para el mismo periodo, la economía se reactiva más rápido por la adecuada gestión que hicieron con la pandemia por COVID-19.

- Por último, se requiere de la creación de políticas públicas que permitan amortiguar los impactos socioeconómicos globales comentados en esta investigación, las principales alternativas son: aplicar con rigurosidad los protocolos de salud pública, testeo para la mayoría de la población y seguimiento de los casos de contagio, aplicar las vacunas que posean todos los estándares y normas de calidad avaladas por laboratorios, retención de trabajo, disminución de carga fiscal para las micro, pequeñas y medianas empresas e implementar un ingreso básico universal en función de las particularidades de cada territorio. Estas propuestas ayudarían a disminuir el riesgo sanitario y económico ante futuras pandemias. 


\section{Bibliografía y referencias documentales}

Acs, G., y Karpman, M. (2020). Employment, Income, and Unemployment Insurance during the COVID-19 Pandemic. Recuperado del sitio web del Urban Institute: https://www.urban.org/sites/default/files/publication/102485/employment-income-andunemployment-insurance-during-the-covid-19-pandemic.pdf

Ahmad, T., Haroon, Baig, M., \& Hui, J. (2020). Coronavirus Disease 2019 (COVID-19) Pandemic and Economic Impact. Pakistan journal of medical sciences, 36(COVID19-S4), S73-S78. https://doi.org/10.12669/pjms.36.COVID19-S4.2638

Anderson, D. R., Sweeney, D. J., Williams, T. A., Camm, J. D., \& Martin, K. (2011). Elaboración de pronósticos. Métodos cuantitativos para los negocios (pp. 181-233). Boston, Massachusetts: Cengage Learning.

Banco Mundial (2020). Global economic prospects. Washington: The World Bank.

Baric, R. S. (2007). SARS-CoV: Lessons for global health. Virus Research Volume 133 (1), 1-3. https://doi.org/10.1016/j.virusres.2007.03.024

Carrada, T (2010). Influenza: Avances recientes en virología molecular y prevención de la enfermedad. Recuperado de https://www.medigraphic.com/pdfs/patol/pt-2010/pt102a.pdf

CDC (2009). Cost-effectiveness Analysis of Hospital Infection Control Response to an Epidemic Respiratory Virus Threat. Recuperado del sitio web del CDC: https://wwwnc.cdc.gov/eid/article/15/12/090902 article

CDC (2010). 2009 H1N1 Flu ("Swine Flu") and You. Recuperado del sitio web del CDC: https://www.cdc.gov/h1n1flu/qa.htm

CDC (2011). Severe Acute Respiratory Syndrome (SARS). Recuperado del sitio web del CDC: https://www.cdc.gov/sars/about/fs-sars.html\#outbreak

CDC (2014). CDC SARS Response Timeline. Recuperado del sitio web del CDC: https://www.cdc.gov/about/history/sars/timeline.htm

CDC (2019) Middle East Respiratory Syndrome (MERS). Recuperado del sitio web del CDC: https://www.cdc.gov/coronavirus/mers/about/index.html

CEPAL (2020). América Latina y el Caribe ante la pandemia del COVID-19. Efectos económicos y sociales. Santiago: Naciones Unidas.

CEPAL (2020). Informe sobre el impacto económico en América Latina y el Caribe de la enfermedad por coronavirus (COVID-19). Santiago: Naciones Unidas.

Chan-Yeung, M., \& Xu, R. H. (2003). SARS: epidemiology. Respirology (Carlton, Vic.), 8 Suppl (Suppl 1), S9-S14. https://doi.org/10.1046/j.1440-1843.2003.00518.x

Chen, W., Mrkaic, M., Nabar, M. (2019). The Global Economic Recovery 10 Years After the 2008 Financial Crisis. Recuperado del sitio web del FMI: https://www.imf.org/en/Publications/WP/Issues/2019/04/26/The-Global-Economic-Recovery-10Years-After-the-2008-Financial-Crisis-46711

Cheng, D. (2020). Covid 19 coronavirus: No new Covid-19 cases for ninth straight day. Recuperado del sitio web del New Zealand Herald: https://www.nzherald.co.nz/nz/news/article.cfm?c_id=1\&objectid=12336107

Coibion, O., Gorodnichenko, Y., y Weber, M. (2020). Labor markets during the COVID-19 crisis: a preliminary view. Recuperado de https://www.nber.org/system/files/working_papers/w27017/w27017.pdf

Cooke, M. (2020). Covid 19 coronavirus: Why is New Zealand's mortality rate so low? Recuperado del sitio web del New Zealand Herald: https://www.nzherald.co.nz/nz/news/article.cfm?c_id=1\&objectid=12324280

Correia, S., Luck S., y Verner, E. (2020). Pandemic depress the Economy, Public Health Interventions Do Not: Evidence form the 1918 Flu. Recuperado de https://papers.ssrn.com/sol3/papers.cfm?abstract_id=3561560

Dawood, F., Luliano, A. D., Reed, C., Meltzer, M. I., Shay, D. K., Cheng, P., ... Widdowson, M. (2012). Estimated. Global mortality associated with the first 12 months of 2009 pandemic influenza A H1N1 virus circulation: a modelling study. The Lancet Infectious Diseases Volume 12 (9), 687-695. https://doi.org/10.1016/S1473-3099(12)70121-4 
Denison, M. R., Graham, R. L., Donaldson, E. F., Eckerle, L. D., \& Baric, R. S. (2011). Coronaviruses: an RNA proofreading machine regulates replication fidelity and diversity. $R N A$ biology, 8(2), 270-279. https://doi.org/10.4161/rna.8.2.15013

Díaz, K. (2019). Evolución socioeconómica de Nueva Zelanda: una aproximación. En Temas de economía mundial (págs. 60-70). Nueva Época II. No. 36. La Habana: Centro de Investigaciones de la Economía Mundial.

FMI (2020). IMF data access to macroeconomic and financial data. Recuperado del sitio web del IMF Data: https://data.imf.org/?sk=388dfa60-1d26-4ade-b505-a05a558d9a42

FMI (2010). IMF Survey: Sharp Rise in Unemployment from Global Recession. Recuperado del sitio web del IMF: https://www.imf.org/en/News/Articles/2015/09/28/04/53/sonew090210a

Government of the Hong Kong Special Administrative Region (2004). Economic Background. Recuperado de https://www.hkeconomy.gov.hk/en/pdf/er_03q4_b.pdf

Guillén, A. (2007). La teoría latinoamericana del desarrollo. Repensar la teoría del desarrollo en un contexto de globalización. Homenaje a Celso Furtado, CLACSO. Universidad Autónoma Metropolitana, Red Eurolatinoamericana de Estudios Sobre el Desarrollo, Buenos Aíres, Argentina.

Health Navigator New Zealand (2020). Severe acute respiratory syndrome (SARS). Recuperado de https:/www.healthnavigator.org.nz/health-a-z/s/severe-acute-respiratory-syndrome-sars

ILO (2004). Global unemployment remains at record levels. In 2003 but annual ILO jobs report sees signs of recovery. Retrieved from ILO website: https://www.ilo.org/global/about-theilo/newsroom/news/WCMS 005187/lang--en/index.htm

ILO (2020). ILO Monitor: COVID-19 and the world of work. Fifth edition. Recuperado del sitio web del ILO: https://www.ilo.org/wcmsp5/groups/public/@dgreports/@dcomm/documents/briefingnote/wcms_74 9399.pdf

Joo, H., Maskery, B. A., Berro, A. D., Rotz, L. D., Lee, Y., Brown, C. M. (2019). Economic impact of the 2015 MERS outbreak on the Republic of Korea's Tourism Related Industries. Health Security, 17, 100-108. https://doi.org/10.1089/hs.2018.0115

Judd, W.S., Campbell, C.S., Kellogg, E.A., Stevens, P.F., Donoghue, M.J. (2007). “Taxonomy”. Plant Systematics: A Phylogenetic Approach (3rd ed.). Sunderland: Sinauer Associates.

King, A. M., Adams, M. J., Carstens, E. B., \& Lefkowitz, E. (Eds.). (2011). Virus taxonomy: Recuperado de https://0-ebookcentral-proquest-com.biblioteca-ils.tec.mx

Lee, J. W., McKibbin, W. J. ESTIMATING THE GLOBAL ECONOMIC COSTS OF SARS. Institute of Medicine (US) Forum on Microbial Threats; Knobler S, Mahmoud A, Lemon S, et al., editors. Learning from SARS: Preparing for the Next Disease Outbreak: Workshop Summary. Washington (DC): National Academies Press (US); 2004. Recuperado de: https://www.ncbi.nlm.nih.gov/books/NBK92473/

Lee, A., \& Cho, J. (2016). The impact of epidemics on labor market: identifying victims of the Middle East Respiratory Syndrome in the Korean labor market. International journal for equity in health, 15 (1), 196. https://doi.org/10.1186/s12939-016-0483-9

Liu S, Ji K, Chen J, Tai D, Jiang W, et al. (2009) Panorama Phylogenetic Diversity and Distribution of Type A Influenza Virus. PLoS ONE 4(3): e5022. doi: 10.1371/journal.pone.0005022

Local Government Association (2020). LGA workforce: coronavirus job retention scheme. Recuperado del sitio web: https://www.local.gov.uk/lga-workforce-coronavirus-job-retention-scheme

McKercher, B., \& Chon, K. (2004). The Over-Reaction to SARS and the Collapse of Asian Tourism. Annals of tourism research, 31(3), 716-719. https://doi.org/10.1016/j.annals.2003.11.002

Ministry for Primary Industries (2020). COVID-19 and the effects on trade. Recuperado del sitio web: https://www.mpi.govt.nz/export/coronavirus-and-the-effects-on-trade/

Ministry of Health (2020). Middle East Respiratory Syndrome Coronavirus (MERS-CoV). Recuperado del sitio web: $\quad$ https://www.health.govt.nz/our-work/diseases-and-conditions/middle-east-respiratorysyndrome-coronavirus-mers-cov

Merriam-Webster (2020) Virus. Recuperado de https://www.merriam-webster.com/dictionary/virus\#h1

New Zealand Government (2004). Economic and Financial Overview 2004. Recuperado del sitio web: https:/www.treasury.govt.nz/sites/default/files/2009-07/nzefo-04.pdf

New Zealand Parliament (2009). Human Influenza A (H1N1) (Swine Flu). Recuperado de https://www.parliament.nz/en/pb/research-papers/document/00PLSoc09041/human-influenza-ah1n1-swine-flu 
New Zealand Government (2016). Economic and Financial Overview 2016. Recuperado del sitio web: https://www.health.govt.nz/our-work/diseases-and-conditions/middle-east-respiratory-syndromecoronavirus-mers-cov

New Zealand Government (2016). Economic and Financial Overview 2016. Recuperado de https://www.treasury.govt.nz/sites/default/files/2010-04/nzefo-16.pdf

OCDE (2020). Gross domestic product (GDP). Recuperado del sitio web del OECD Data: https://data.oecd.org/gdp/gross-domestic-product-gdp.htm

OCDE (2020). Job retention schemes during the COVID-19 lockdown and beyong. Recuperado del sitio web de la Organización para la Cooperación y el Desarrollo Económicos: http://www.oecd.org/coronavirus/policy-responses/job-retention-schemes-during-the-covid-19lockdown-and-beyond-0853bald/

Office for National Statistics (2017). Claimant count QMI. Recuperado del sitio web: https://www.ons.gov.uk/employmentandlabourmarket/peopleinwork/employmentandemployeetypes/ methodologies/claimantcountqmi

OMC (2020). El comercio se contrae de forma acusada en la primera mitad de 2020. Recuperado del sitio web de la OMC: https://www.wto.org/spanish/news_s/pres20_s/pr858_s.htm

OMS (2004). WHO guidelines for the global surveillance of severe acute respiratory syndrome (SARS). Updated recommendations. Recuperado https://www.who.int/csr/resources/publications/WHO_CDS_CSR_ARO_2004_1.pdf?ua=1

OMS (2010). What is a pandemic? https://www.who.int/csr/disease/swineflu/frequently_asked_questions/pandemic/en/

OPEC (2020). Saudi Arabia facts and figures. Recuperado del sitio web del OPEC: https://www.opec.org/opec_web/en/about us/169.htm

OPS, OMS (2020). La OMS caracteriza a COVID-19 como una pandemia. Recuperado del sitio web de la Organización Panamericana de la Salud: https://www.paho.org/es/noticias/11-3-2020-omscaracteriza-covid-19-como-pandemia

Parkin, M. (2018). Economía. México: Pearson Educación de México, S.A. de C.V.

Petersen, E., Koopmans, M., Go, U., Hammer, D., Petrosillo, N., Castelli, F., ... Simonsen, L. (2020). Comparing SARS-CoV-2 with SARS- CoV and influenza pandemics. Recuperado de sitio web: https://www.ons.gov.uk/employmentandlabourmarket/peopleinwork/employmentandemployeetypes/ methodologies/claimantcountqmi

Statistics New Zealand (2009). Global New Zealand - International Trade, Investment, and Travel Profile: Year ended $2009 . \quad$ June Recuperado de http://archive.stats.govt.nz/browse_for_stats/industry_sectors/imports_and_exports/global-nz-jun09/key-points.aspx\#gsc.tab $=0$

Statistics New Zealand (2012). The New Zealand labour market during recession. Recuperado de http://archive.stats.govt.nz/browse_for_stats/income-and work/employment_and_unemployment/nzlabour-market-during-recession.aspx\#gsc.tab $=0$

Statistics New Zealand (2020). COVID-19 lockdown has widespread effects on labour market. Recuperado de https://www.stats.govt.nz/news/covid-19-lockdown-has-widespread-effects-on-labour-market

Talha, J., Radia, J., Abdul, S. (2020). H1N1 Influenza (Swine Flu). Recuperado de https://www.ncbi.nlm.nih.gov/books/NBK513241/

The World Bank (2020). The Global Economic Outlook During the COVID-19 Pandemic: A Changed World. Recuperado del sitio web del World Bank: https://www.worldbank.org/en/news/feature/2020/06/08/the-global-economic-outlook-during-thecovid-19-pandemic-a-changed-world

The New York Times (2010) Timeline of Major Events in the Iraq War. Recuperado del sitio web del New York Times: https://archive.nytimes.com/www.nytimes.com/interactive/2010/08/31/world/middleeast/20100831Iraq-Timeline.html?_r=1\#/\#time111_3264

Tisdell C. A. (2020). Economic, social and political issues raised by the COVID-19 pandemic. Economic analysis and policy, 68, 17-28. https://doi.org/10.1016/j.eap.2020.08.002

UN (2012). World Economic Situation and Prospects 2012. Recuperado de https://www.un.org/en/development/desa/policy/wesp/wesp_archive/2012wespupdate.pdf 
UN (2014). World Economic Situation and Prospects 2014 . Recuperado de https:/www.un.org/en/development/desa/policy/wesp/wesp_current/WESP2014 midyear_update.pdf

United Nations Development Programme (2020) Human Development Index (HDI). Recuperado del sitio web de Human Development Reports: http://hdr.undp.org/en/content/human-development-index-hdi

US National Library of Medicine (2020). H1N1influenza (Swine flu). Recuperado del sitio web de MedlinePlus: https://medlineplus.gov/ency/article/007421.htm

Van Parijs, P. (1992). “Arguing for basic income”, en Philippe Van Parijs, Competing Justifications of Basic Income, London, Verso, pp. 3-29.

Villarreal, N. (2020). Diálogo global: Desarrollo, bienestar y renta básica universal. Recuperado del sitio web de la Red Iberoamericana de Estudios del Desarrollo: https://riedesarrollo.org/dialogo-globaldesarrollo-bienestar-y-renta-basica-universal/

WHO (2020). Epidemic and pandemic-prone diseases: MERS situation update, January 2020. Recuperado del sitio web del WHO: http://www.emro.who.int/pandemic-epidemic-diseases/mers-cov/mers-situationupdate-january-2020.html

WHO (2020). Estimating mortality from COVID-19. Recuperado del sitio web del WHO: https:/www.who.int/news-room/commentaries/detail/estimating-mortality-from-covid-19

Wilson, N., Kvalsvig, A., Barnard, L., \& Baker, M. G. (2020). Case-Fatality Risk Estimates for COVID-19 Calculated by Using a Lag Time for Fatality. Emerging Infectious Diseases, 26(6), 1339-1441. https://dx.doi.org/10.3201/eid2606.200320.

Wong, J. Y., Kelly, H., Ip, D. K., Wu, J. T., Leung, G. M., \& Cowling, B. J. (2013). Case fatality risk of influenza A (H1N1pdm09): a systematic review. Epidemiology (Cambridge, Mass.), 24(6), 830-841. https://doi.org/10.1097/EDE.0b013e3182a67448

WTO (2009). WTO sees 9\% global trade decline in 2009 as recession strikes. Recuperado del sitio web de WTO: https://www.wto.org/english/news_e/pres09_e/pr554_e.htm

$\mathrm{Xu}, \quad$ R., Chang-Yeung, M. (2003). SARS: epidemiology. Respirology Volume 8 (1). https://doi.org/10.1046/j.1440-1843.2003.00518.x

Yánez, P. (2020). Diálogo global: Desarrollo, bienestar y renta básica universal. Recuperado del sitio web de la Red Iberoamericana de Estudios del Desarrollo: https://riedesarrollo.org/dialogo-global-desarrollobienestar-y-renta-basica-universal/

Zhang, Y. (2008). Encyclopedia of Global Health (4 Vol. Set). Sage. Recuperado de http://sk.sagepub.com/reference/globalhealth 


\section{Números anteriores}

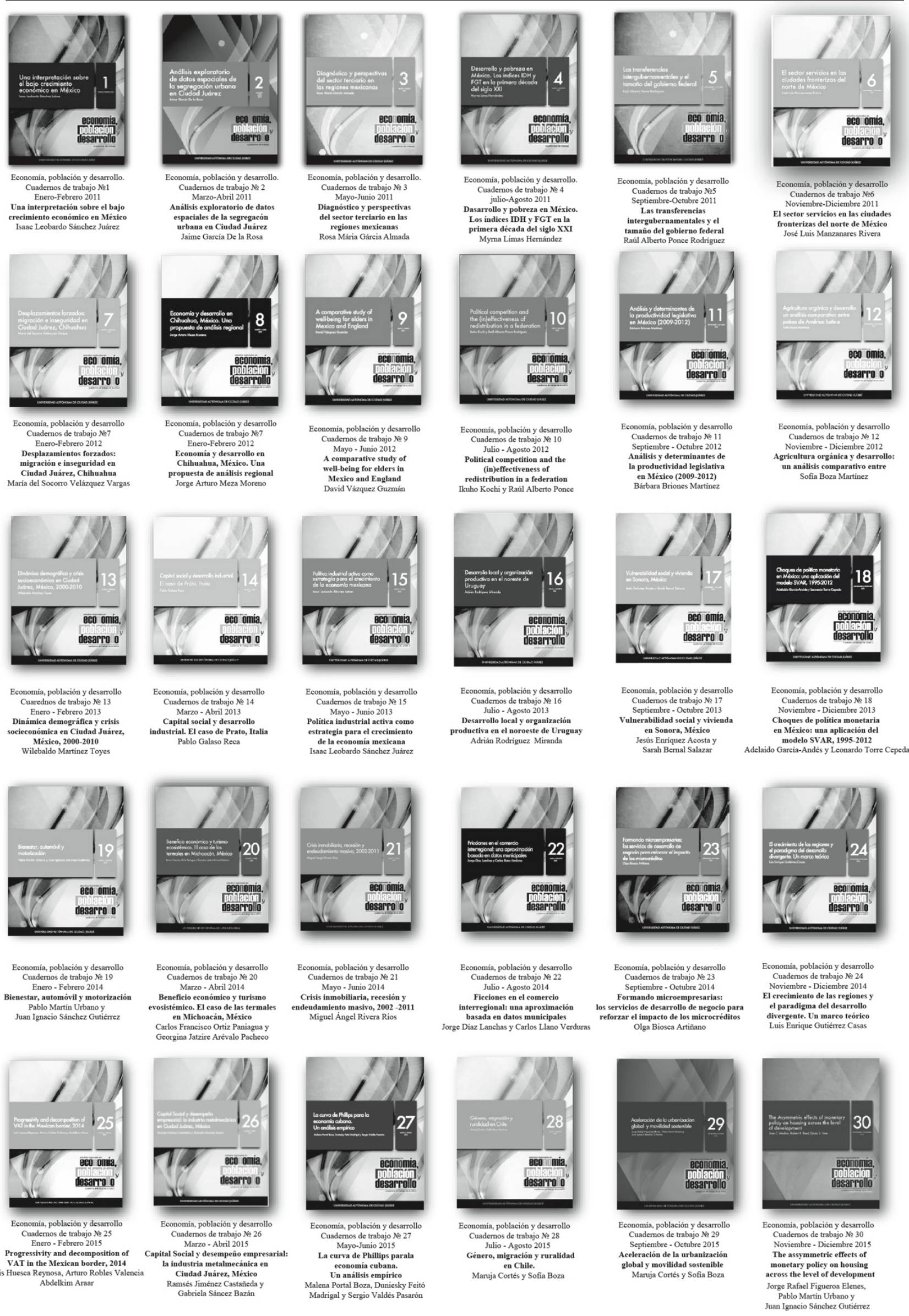



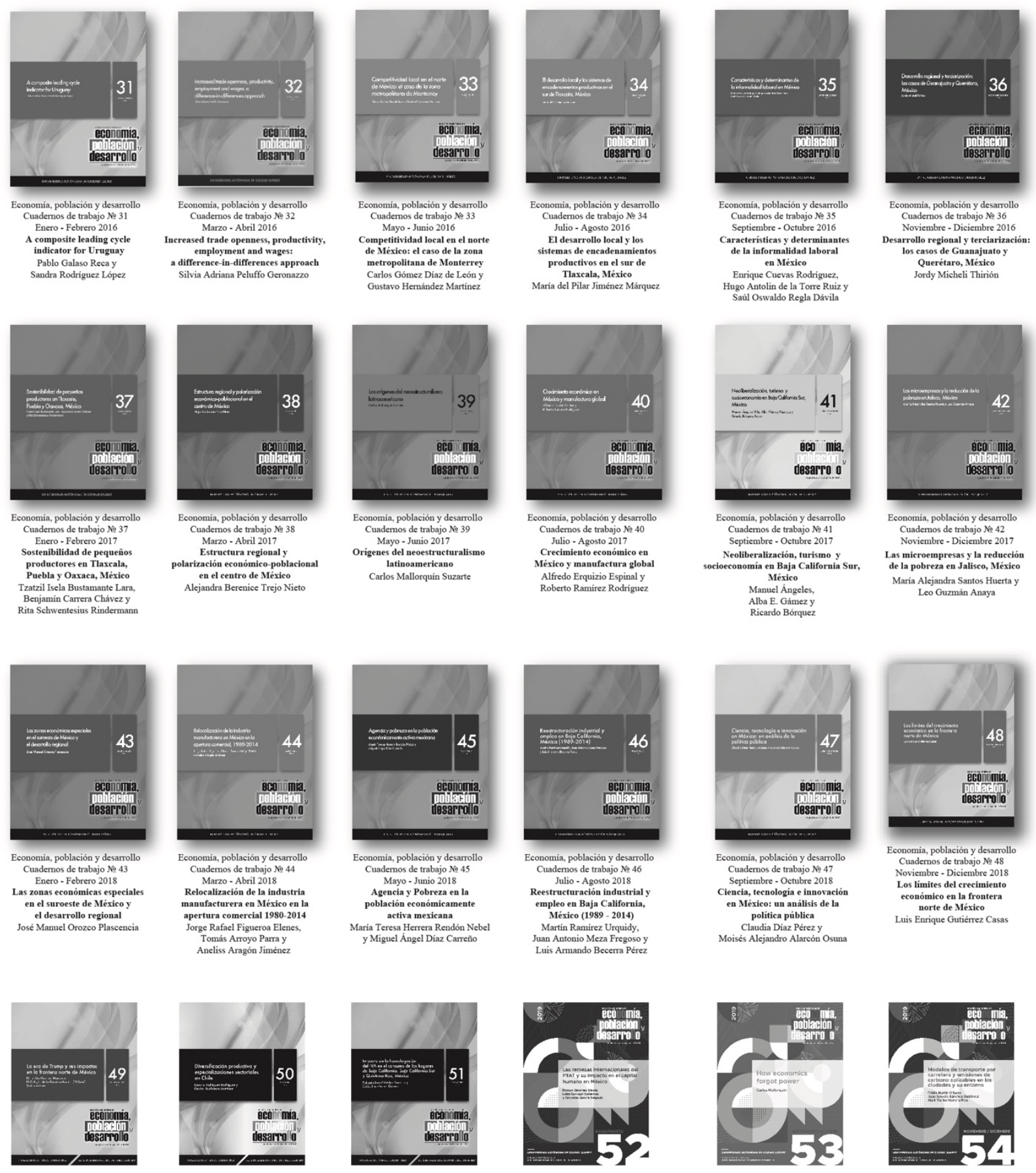

Economia, población y desararollo
Cuadernos de trabajo No 49
Enero - Febrero 2019

La era de Trump y sus impactos
en la frontera norte de Mérico

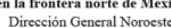

Varios autores

Economia, población y desarrollo
Cuadernos de trabajo № 50 Marzo - Abril 2019 Diversificación productiva y
especializaciones sectoriales Ignacio Rodriguez Rodriguez
Paulina Sanhlueza Martinez

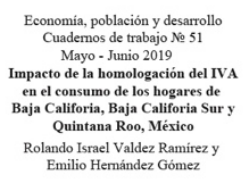

Economia, población y desarrollo
Cuadernos de trabajo Ne 52 Julio - Agosto 2019

Las remesas internacionales
del PTAT $y$ su impacto en Román Sánchez Dáv Romain Sánchez Dávila
Lidia Carvajal Gutiérec y
Oswaldo Garcia Salgado
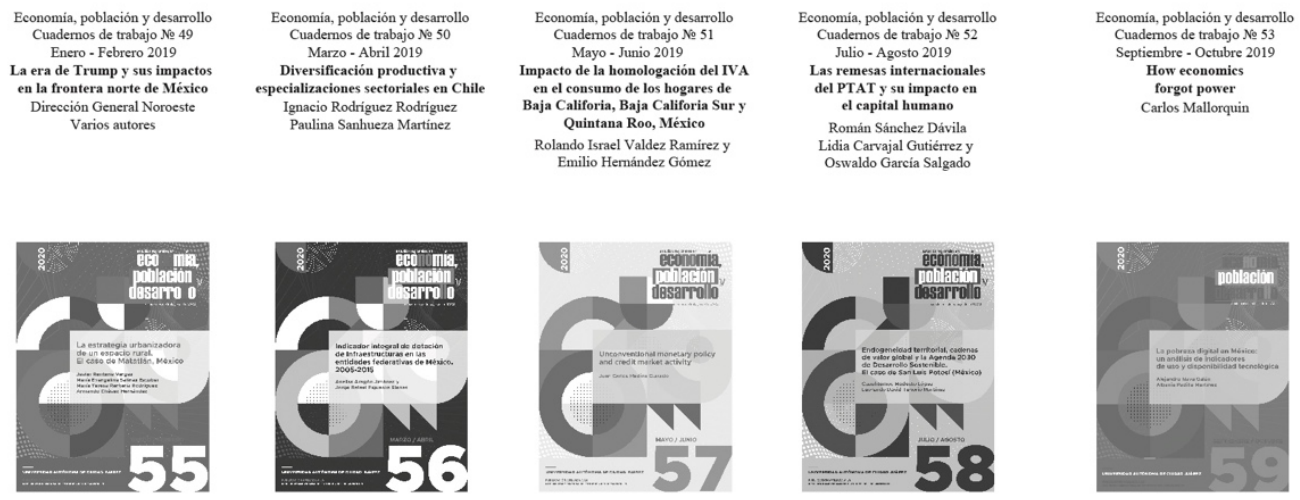

Economia, población y desarrollo
Cuadernos de trabajo No 54 Noviembre - Diciembre 2019
Modelos de transporte por carretera Modelos de transporte por carreteray
emisiones de carbono aplicables en las ciudades y su entorno Pablo Martin Urbano,
Juan Ignacio Sánchez Gutiérres y Abril Yuriko Herrera Ríos

Economia, población y desarrollo Enero - Febrero 2020 La estrategia urbanizadora de un espacio rural.
El caso de Matatlán, México. Javier Renteria Vargas, Maria Evangelina Salinas Escobar,
Maria Teresa Renteria Rodriguez Amando Chávez Hernande:

\section{Economia, población y desarrollo} Mayo - Junio 2020

Unconventional monetary policy
and creditmarket activity Juan Carlos Medina Guirado
Economia, población y desarrollo Julio - Agosto 2020 Endogeneidad territorial, cadenas de valor global y la
Agenda 2030 de Desarrollo Sostenible. Agenda 2030 de Desarrollo Sostenible
El caso de San Luis Potosi (México) Cuauhtémoc Modesto López y
Leonardo David Tenorio Martinez
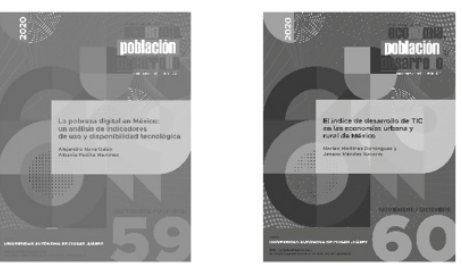

Economiá, población y desarrollo Septiembre - Octubre 2020 La pobreza digital en México: un analisisis de indicadores de uso
disponibilidad tecnologica Alejandro Nava Galann y
Albania Padilla Martinez
Economia, población y desarrollo TIC en las economías
urbana y rural de México Marlen Martinez Domingue zy El indice de desarrollo de 
Números anteriores

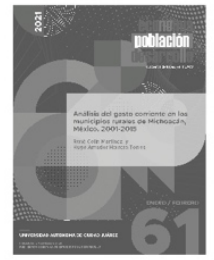

Economia, población y desarrollo
Cuadernos de trabajo № 61 Cuadernos de trabajo № 61
Enero - Febrero 2021
álisis del gasto corriente

municipios rurales de Michoacán,

México, 2001-2015

René Colin Martinez y
Hugo Amador Herrera Torres 


\section{Para el documento general:}

Tipo de letra: Times New Roman.

Tamaño: 11 puntos.

Interlineado: 1.5 espacios.

Títulos y subtítulos:

El texto principal en 11 puntos. Títulos 12 puntos (en resaltado). Subtítulos 11 puntos. Cada título y subtítulo deberá numerarse bajo el siguiente orden: 1, 1.1, 2, 2.1, 2.2...

La extensión máxima de los cuadernos de trabajo será de 40 cuartillas.

La primera vez que se emplee una sigla en el texto se especificará primero su equivalencia completa y después la sigla.

\section{Hoja de presentación:}

Título:

14 puntos, centrado, resaltado.

Nombre de autor(es):

12 puntos

Resumen y abstract:

Debe incluir resumen en español y abstract (diez puntos), no mayor a 250 palabras

Palabras clave:

Incluir entre tres y cinco palabras clave, en español e inglés

Referencia del autor o autores:

Institución de adscripción, grado académico y líneas-grupos de investigación que desarrolla y a los que pertenece.

\section{Sistema de referencia de citas:}

Harvard-APA

Las citas bibliográficas en el texto deberán incluir entre paréntesis sólo el apellido del autor, la fecha de publicación y el número de página; por ejemplo: (Quilodrán, 2001: 33).

\section{Notación en sección de bibliografía y fuentes de información:}

Se deberá incluir al final del texto. Toda referencia deberá estar mencionada en el texto o notas de pie de página.

Cada referencia iniciará con el primer apellido o los apellidos, luego el nombre del autor, y después, entre paréntesis, el año de publicación seguido de un punto. Ejemplos:

Se deberá incluir al final del texto. Toda referencia deberá estar mencionada en el texto o notas de pie de página.

Cada referencia iniciará con el primer apellido o los apellidos, luego el nombre del autor, y después, entre paréntesis, el año de publicación seguido de un punto. Ejemplos: 
Artículo:

Ros, Jaime (2008). "La desaceleración del crecimiento económico en México desde 1982”, en Trimestre Económico, vol. 75, núm. 299, pp. 537-560.

Libro:

Villarreal, René (2005). Industrialización, competitividad y desequilibrio externo en México.

Un enfoque macroindustrial y financiero (1929-2010), México, Fondo de Cultura Económica.

Capítulo de libro:

Castillo, Manuel Ángel (2003). "La política de inmigración en México: un breve recuento", en Manuel Ángel Castillo, Alfredo Lattes y Jorge Santibáñez (coords.), Migración y fronteras, Tijuana,

El Colegio de la Frontera Norte / Asociación Latinoamericana de Sociología / El Colegio de México, pp. $425-451$.

\section{Notas de pie de página:}

Se utilizarán para hacer indicaciones complementarias, aclaraciones o ampliación de una explicación. La nota de pie de página en Times New Roman, 10 puntos.

\section{Tipología de imágenes dentro del texto:}

Cuadro

Gráfica

Diagrama

Mapa

Figura

Todas las imágenes deben ser numeradas y mencionadas dentro del texto. A toda imagen debe incluirse la fuente.

Las indicaciones de la imagen: tipo y número de imagen, título de imagen y fuente se escriben en 10 puntos. En el texto poner como imagen los mapas, figuras, gráficas y diagramas -con el ánimo de no perder el formato realizado por el autor.

\section{Ecuaciones y fórmulas:}

Si se utilizan ecuaciones o fórmulas deberá utilizarse el editor de ecuaciones de Word y numerarse.

\section{Envío de trabajos}

Los trabajos deben ser enviados a la dirección de correo: lgtz@uacj.mx. Con el Dr. Luis Enrique Gutiérrez Casas, editor de esta publicación.

La aceptación de cada colaboración dependerá de la evaluación de dos dictaminadores especialistas en la materia que se conservarán en el anonimato, al igual que el autor (autores) para efectos de la misma. 


\section{For General Document:}

Font type: Times New Roman.

Size: font size 11 .

Paragraph: 1.5 line spacing.

Titles and subtitles: Main text font size 11. Titles font size 12 (Bold). Subtitles font size 11.

Each title and subtitle should be numbered in the following order: 1, 1.1, 2, 2.1, 2.2...

The maximum length of the workbooks will be 40 pages.

The first time an abbreviation is used in the text will be specified first complete equivalence and then stands.

\section{Front cover:}

Title:

Font size 14, centered, Bold.

Author name(s):

Font size 12.

Abstract:

It should include abstract in Spanish and abstract (font size 10), no more than 250 words.

Keywords:

Include three to five keywords, in Spanish and English.

Reference of author:

Institution of affiliation, academic degree and line-developed by research groups and belonging.

\section{Bibliographical appointment system:}

Harvard-APA

Citations in the text should include between parentheses only the author's name, publication date and page number, for example:

(Quilodrán, 2001: 33).

\section{Notation about Bibliography section and Information fonts:}

Should be included at the end of the text. All references must be mentioned in the text or footnotes page.

Each reference starts with the first name or last name, then the name of the author, and then, in parentheses, the year of publication followed by a period. Examples:

Article:

Ros, Jaime (2008). "La desaceleración del crecimiento económico en México desde 1982”, en Trimestre Económico, vol. 75, núm. 299, pp. 537-560. 


\section{Editorial Guidelines}

Book:

Villarreal, René (2005). Industrialización, competitividad y desequilibrio externo en México. Un enfoque macroindustrial y financiero (1929-2010), México, Fondo de Cultura Económica.

Book chapter:

Castillo, Manuel Ángel (2003). "La política de inmigración en México: un breve recuento", en Manuel Ángel Castillo, Alfredo Lattes y Jorge Santibáñez (coords.), Migración y fronteras, Tijuana, El Colegio de la Frontera Norte / Asociación Latinoamericana de Sociología / El Colegio de México, pp. $425-451$.

\section{Footnotes:}

Must be used to make additional indications, clarification or expansion of an explanation. The footnotes must be in Times New Roman, font size 10.

\section{Image typology inside text:}

Picture

Graph

Diagram

Map

Figure

All images must be numbered and mentioned in the text, should include the source image. The indications of the image: type and number of image, image title and source are written in 10 font size. In the text set as image maps, figures, graphs and charts-with the intention of not losing the formatting by the author.

\section{Equations and Formulae:}

When using equations or formulas should be used in Microsoft Word equation editor and numbered.

\section{Paper sending}

Entries must be sent to the email address: lgtz@uacj.mx. With Dr. Luis Enrique Gutiérrez Casas, editor of this publication.

Acceptance of each collaboration will depend on the evaluation of two examiners skilled in the art to be kept anonymous, like the author(s) for the same purposes. 
Publicación afiliada a la

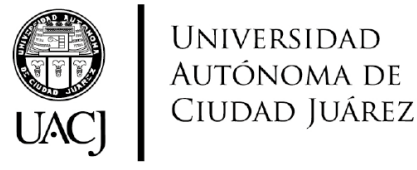

Red
RIED

Esta obra se editó y terminó de imprimir en Ciudad Juárez, Chihuahua, México 


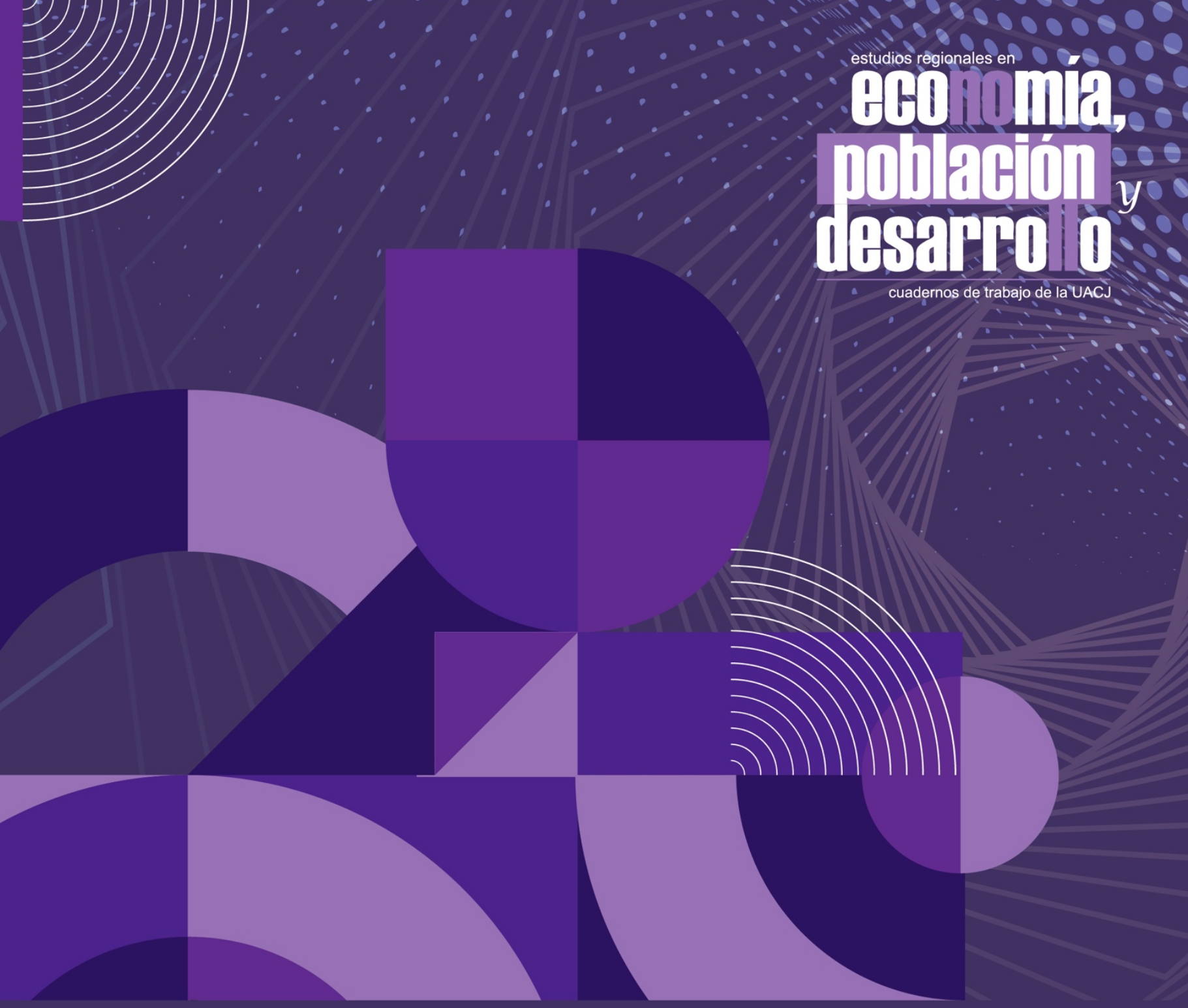

\section{Cuadernos de Trabajo de la Universidad Autónoma de Ciudad Juárez, número 62, marzo - abril de 2021}

\section{Director y editor}

Dr. Luis Enrique Gutiérrez Casas

\section{Comité editorial}

\section{Sección internacional}

Dra. Sofía Boza Martínez (Universidad de Chile, Chile)

Dra. Olga Biosca Artiñano (Glasgow Caledonian University, Reino Unido)

Dra. Ángeles Sánchez Díez (Universidad Autónoma de Madrid, España)

Dr. Thomas Fullerton Mankin (University of Texas at El Paso, Estados Unidos)

Dr. Adrián Rodríguez Miranda (Universidad de la República, Uruguay)

Dra. Ikuho Kochi (Kanazawa University, Japón)

Dr. Pablo Galaso Reca (Universidad de la República, Uruguay)

\section{Sección local}

(Universidad Autónoma de Ciudad Juárez)

Dra. Myrna Limas Hernández

Dra. Rosa María García Almada

Dr. Raúl Alberto Ponce Rodríguez

Dr. Isaac Leobardo Sánchez Juárez

Dr. Héctor Alonso Barajas Bustillos

Dr. Juan Carlos Medina Guirado

Mtra. María Del Socorro Velázquez Vargas

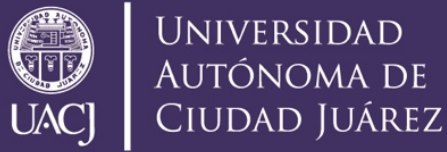

Universidad Autónoma de Ciudad Juárez Cuadernos de Estudios Regionales en Economía, Población y Desarrollo ISSN 2007-3739

Edición impresa:

ISSN 2007-3739

Edición digital:

No. de reserva 04-2019-050218151500

www.riedesarrollo.org

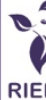

Iberoamerican de Estudios del Desarrollo

Publicación afiliada a la Red Iberoamericana de Estudios del Desarrollo

(c) Universidad Autónoma de Ciudad Juárez Avenida Plutarco Elías Calles \#1210, Fovissste Chamizal Ciudad Juárez, Chih., México. www.uacj.mx 